


\section{Adoption of food loss and waste-reducing interventions in Low- and Middle-Income Countries}

Authors: dr. ir. J.M. (Han) Soethoudt, dr. M. (Michele) Pedrotti, dr. H.E.J. (Hilke) Bos-Brouwers, dr. R.B. (Bob) Castelein

Institute: WFBR

This study was carried out by Wageningen Food \& Biobased Research, subsidised by the Dutch Ministry of Agriculture, Nature and Food Quality and funded by the Rockefeller Foundation, and the Foundation for Food and Agriculture Research.

Wageningen Food \& Biobased Research

Wageningen, August 2021

Public

Report 2196 
WFBR Project number: 6239177200

BAPS number: KB-35-002-001-WEcR

Version: Final

Reviewer: D.M. (Vera) Vernooij MSc

Approved by: dr. ir. H. (Henk) Wensink

Subsidised by: the Dutch Ministry of Agriculture, Nature and Food Quality

Funded by: the Rockefeller Foundation, and the Foundation for Food and Agriculture Research

This report is: public

The research that is documented in this report was conducted in an objective way by researchers who act impartial with respect to the client(s) and sponsor(s). This report can be downloaded for free at https://doi.org/10.18174/554051 or at www.wur.eu/wfbr (under publications).

(C) 2021 Wageningen Food \& Biobased Research, institute within the legal entity Stichting Wageningen Research.

The client is entitled to disclose this report in full and make it available to third parties for review. Without prior written consent from Wageningen Food \& Biobased Research, it is not permitted to:

a. partially publish this report created by Wageningen Food \& Biobased Research or partially disclose it in any other way;

b. use this report for the purposes of making claims, conducting legal procedures, for (negative) publicity, and for recruitment in a more general sense;

c. use the name of Wageningen Food \& Biobased Research in a different sense than as the author of this report.

PO box 17, 6700 AA Wageningen, The Netherlands, T + 31 (0)317 4800 84, E info.wfbr@wur.nl, www.wur.eu/wfbr.

All rights reserved. No part of this publication may be reproduced, stored in a retrieval system of any nature, or transmitted, in any form or by any means, electronic, mechanical, photocopying, recording or otherwise, without the prior permission of the publisher. The publisher does not accept any liability for inaccuracies in this report. 


\section{Contents}

$\begin{array}{lc}\text { Acknowledgements } & 4\end{array}$

$\begin{array}{lr}\text { Abstract } & 5\end{array}$

$\begin{array}{llr}1 & \text { Introduction } & 6\end{array}$

$2 \quad$ The context: food losses in LMICs $\quad 10$

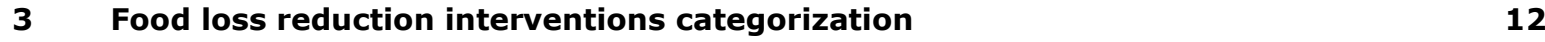

3.1 The intervention level 12

$\begin{array}{ll}3.2 & \text { The intervention actors } \\ 3.3 & 13\end{array}$

3.3 The intervention types $\quad 14$

3.3.1 Technology 14

3.3.2 Finance and investment 16

$\begin{array}{lll}3.3 .3 & \text { Best practices } & 16\end{array}$

$\begin{array}{lll}3.3 .4 & \text { Organization } & 17\end{array}$

3.3.5 Policy 18

$\begin{array}{ll}\text { 3.3.6 Economics } & 19\end{array}$

$\begin{array}{lll}3.4 & \text { Intervention evaluation } & 20\end{array}$

3.4.1 Adoption criteria for FLW reduction interventions $\quad 21$

$\begin{array}{lll}3.4 .2 & \text { Food system considerations } & 23\end{array}$

4 Case studies $r 2$

$\begin{array}{lll}4.1 & \text { Crates for tomatoes in Nigeria } & 25\end{array}$

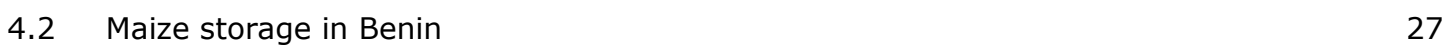

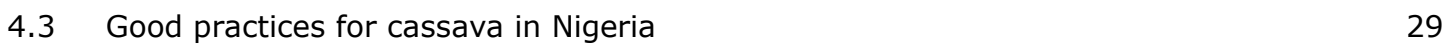

$\begin{array}{lll}4.4 & \text { Shallot planting and curing in Indonesia } & 31\end{array}$

$5 \quad$ Conclusions and further research $\quad 34$

$\begin{array}{ll}\text { Literature } & 36\end{array}$ 


\section{Acknowledgements}

This research was carried out within the motif 'Feeding cities and migration settlements' (2282700540), as part of the programme Food Security and Valuing Water (KB-35-002-001) of Wageningen University \& Research and was supported by the Dutch Ministry of Agriculture, Nature and Food Quality and project 'Consortium for Innovation in Post-Harvest Loss and Food Waste Reduction - Innovation Platform to Gain Sustainable Efficiencies in the Global Food System' funded by grants from The Rockefeller Foundation (Grant 2018 FOD 004) and the Foundation for Food and Agriculture Research (Grant DFs-18-0000000008). 


\section{Abstract}

The target of the Sustainable Development Goal 12.3 calls for halving per capita food loss and waste (FLW) by 2030 . During the past decade, the reduction of FLW gained much attention from research in its context of food security and environmental impact. Worldwide, in developed and less developed countries governments and supply chain stakeholders are putting in effort to achieve this goal along supply chains and across product categories. What can be learned from these efforts? In this paper interventions to reduce FLW are discussed, with a focus on Low- and Middle-Income Countries (LMIC) in Sub-Saharan Africa and South East Asia - countries with high losses in early stages of food value chains. Interventions are characterized, structured and evaluated based on literature and a framework is presented to evaluate their effectiveness and context appropriateness to prevent FLW at the local, regional, and national levels, by focusing on factors determining the likelihood of an FLW-reducing intervention being successfully adopted. This paper illustrates the framework using four case studies from Nigeria, Benin, and Indonesia. An important consideration for FLW interventions within the LMIC context, is the observation that economic drivers are predominant over other considerations on feasibility and implementation. This publication is intended to support the scientific and practitioners' communities as well as governmental organisations with insights on the design of interventions within the setting of LMICs. 


\section{Introduction}

Worldwide, initiatives to mitigate food loss and waste (FLW) are intensifying, especially since the Sustainable Development Goals (SDGs) were presented in 2015. Reducing FLW is critical to achieve sustainable food systems and has been recognized by the United Nations as a key contributing factor to reach different SDGs including SDG 2 (zero hunger), SDG 6 (sustainable water management), SDG 12 (sustainable use of resources), SDG 13 (mitigate climate change), SDG 14 (sustainably manage and protect marine resources), and SDG 15 (sustainably manage and protect terrestrial ecosystems) (United Nations, 2015a). To reduce FLW specifically, SDG Target 12.3 has been introduced, aiming to halve per capita global food waste at the retail and consumer levels and reducing food loss along production and supply chains, including post-harvest losses, by 2030 . Progress on this target 12.3 is measured by two separate indicators, namely the Food Loss Index (FLI) (an estimation of how much food is lost in production or in the supply chain before it reaches the retail level) and the Food Waste Index (measuring food waste per capita at the retail and consumer levels).

Achieving a FLW reduction of $30 \%$ has environmental, economic, and social benefits, specifically with regard to food security. Food waste represents between 8 and $10 \%$ of global Greenhouse Gas (GHG) emissions (approx. 3.3. billion tons per year), which - comparing to countries' emissions - is the third-largest emitter of GHG emissions on the planet after China and the United States (X. Guo et al., 2020; IPCC, 2020). Halving the FLW by 2050 would lower GHG emissions by 1.5 gigatons ( 1.5 billion metric tons) of carbon dioxide equivalent ( $\mathrm{CO}_{2}$-eq.) per year by 2050 , an amount more than the energy- and industry-related emissions of Japan (Searchinger et al., 2018). Global FLW is also an economic problem which has been estimated to cost approximately 2.6 trillion US dollars annually (including 1 trillion dollars of economic costs, 900 billion dollars of social costs and 700 billion dollars of environmental costs), and reducing FLW is therefore also economically beneficial. With regard to food security, currently approximately 820 million people still lack sufficient food (FAO et al., 2020). Specifically, $22.8 \%$ and $14.7 \%$ of the overall populations of Sub-Saharan Africa (SSA) and South Asia are undernourished, respectively (FAO, 2015). Moreover, considering the dramatic demographic shift that is taking place especially in Africa and Asia - with a projected increase in population over the coming 15 years of $42 \%$ in Africa and of $12 \%$ in Asia (United Nations, 2015b) - together with the increasing trends toward urbanization and migration in these regions, an extraordinary pressure will be put on the food systems. Therefore, it is essential to further intensify interventions to reduce especially FLW in these areas.

Because of the potential environmental and socio-economic benefits of reducing FLW, both public and private sectors are implementing (or planning) different strategies and actions to address FLW and improve food system efficiencies, including food security. For example, in 2014, the African Union established the Post-Harvest Loss (PHL) Management Strategy, which combines all interventions across the entire food supply chain that aim to reduce post-harvest losses of food crops, including grains, fruit, vegetables and oilseeds, and animal and fishery products (FAO, 2019b). To connect a quantitative ambition to this strategy, the African Union also pledged to halve postharvest food losses by 2025 under the Malabo Declaration (AUC, 2014). Primarily for food security reasons, considerable international funding has been made available for FLW-reducing interventions by for example the World Bank, the Asian Development Bank (ADB), African Development Bank (AfDB), the Rockefeller Foundation and the European Union (EU). This indicates the political momentum to invest in FLW reduction, driven by the SDGs.

However, various challenges arise when designing interventions to reduce FLW. First, there is a lack of sufficiently detailed data to quantify FLW and associated GHG emissions. This complicates targeted interventions at hotspots of the system and data-based decision support when planning interventions to reduce FLW (X. Guo et al., 2020). Secondly, there is no globally agreed-upon definition of FLW, leading to difficulties in comparing studies that use different definitions (Xue et al., 2017). Various studies have attempted to streamline this and suggested data collection and monitoring approaches (R. Hodges, 2013; B Lipinski et al., 2016; Muth et al., 2019; Xue et al., 2017). Still, food loss data for specific product categories is highly fragmented, and studies often focus on one or a few products, 
provide limited statistics (e.g. only one or a few data points). There is also an unbalanced focus on the different stages of the food supply chain: while food waste studies at the retail and consumer level are abundantly available, especially in high-income countries, there are fewer studies addressing PHL in Low- and Middle-Income countries (LMIC) (Affognon et al., 2015; Xue et al., 2017), reflecting the fact that most research is still carried out in high-income regions. Operational conditions make it easier to do research in developed countries, with high quality statistics (up to date, reliable, detailed), significant funding on national level for national research, and companies (with considerable capabilities) willing and prepared to upgrade and prioritize their environmental performance by reducing FLW in their supply chains. In an LMIC context, it is much more difficult to conduct research of similar quality. This is not only due to the quality of institutions and statistics and availability of funding, but also due to structural differences in FLW streams (B Lipinski et al., 2016) and food value chains (Trienekens, 2011) between higher income countries and LMIC.

It therefore remains a challenge to design appropriate FLW reducing interventions that account for differences in FLW existing between countries, sectors, and supply chains, for example influenced by level of income, urbanization, economic growth, and characteristics of the food system. LMIC require a different approach than higher-income regions. Despite the good intentions, great potential and urgency of FLW-reducing interventions in LMIC, there is the danger of investing in so-called 'white elephants': investments that seem promising on paper, but cannot be put to useful work in the implementation context, and often impoverish the recipient with the burden of maintenance and upkeep. These interventions are typically initiated for reasons such as employment or economic development, with FLW reduction as a side effect. To avoid wasted effort, and to implement interventions that have a higher chance of success in the implementation context, it is worthwhile to investigate other conditions related to the investment that may play a role in its success or failure. For example, Klink (2015) evaluated the adoption of interventions to reduce FLW in LMICs, stressing the importance of inclusive interventions, where critical success factors (e.g. affordability and accessibility) are identified for the sustained adaptation of such an intervention. This study aims to contribute to this and further inform effective and sustainable FLW reduction intervention design in LMIC.

The above highlights the importance of reducing PHLs for all food system outcomes (socio-economic, environmental, and food security) (Berkum et al., 2018) and invites the following question: How can context-appropriate food loss-reducing interventions better be selected and designed, to maximize their chance of success? Based on literature, we characterize and structure food loss reducing interventions and present a framework to evaluate their effectiveness and context appropriateness to reduce FLW at the local, regional, and national levels. Only interventions which directly aim to reduce food losses in both quantitative (physical loss) and qualitative (e.g. damage, contamination, deterioration in nutrient contents) terms are considered. Success is defined in the context of the positive economic, social, and environmental impact, that can be sustained in the implementation context when external support is reduced. We then apply our framework to four case studies of interventions implemented in LMIC, namely in Nigeria, Benin, and Indonesia. These were selected based on the good availability of information and focus on a crop with significant losses. Moreover, they represent a wide range of different types of interventions at different levels in the food chain. This study is not a full review of food loss-reducing interventions and their impact which have been summarized elsewhere (see for example the recent review by Stathers et al. (Stathers et al., 2020)).

Important characteristics of LMIC food systems are a) the large share of the rural areas and limited infrastructure, decreasing the accessibility of markets for farmers, b) the supply driven markets, that still play a major role in the food system of these countries, c) linkages in these supply driven markets tend to be weak and vary per day, so monitoring is difficult and intervention efforts are not easy to allocate, and d) the sizes of the farmers production areas are small, whereas their practices and performances are diverse and their numbers are huge. Due to the limited size of the farms and of the production, the value chains are long and complex, efficiency is low, and food losses are high. This can lead to relatively low prices being paid at the production part of the chain, often resulting in minimal investments in production- or quality improvement, efficiency, or loss reduction. In LMIC food losses 'near the farm' are relatively greater, while food waste 'near the plate' is relatively greater in higherincome regions (B Lipinski et al., 2016) - notwithstanding that food waste problems can also be 
prevalent in low- and middle-income regions (UNEP, 2021). Greater food losses in LMIC are mainly caused by poor production, harvesting, and post-harvest practices, technical and technological limitations, labor and financial restrictions, and lack of proper infrastructure for transportation and storage (FAO, 2011; B Lipinski et al., 2016). In LMICs rural populations depend heavily on food production for their income, and food purchases make up a large portion of expenditures in both rural and urban areas. PHL or food losses erode incomes along the food supply chain and may exacerbate the vulnerability of poverty-ridden rural communities. Besides environmental benefits (reduced emissions from resource use) and food security benefits (greater availability of food), PHL reduction can optimize agricultural productivity and potentially increase the incomes of small-scale food producers and associated value-chain actors (Stathers et al., 2020). Namely, increased profits from more availability of food products for sale can be invested in upgrading production practices, which can then again reduce FLW later in the supply chain.

In this paper we use the definitions used in the Food Loss and Food Waste indices (FAO, 2019b, p. xii) that are also part of the SDG framework. Food loss is defined by the FAO as "the decrease in the quantity or quality of food resulting from decisions and actions by food suppliers in the chain, excluding retail, food service providers and consumers" (FAO, 2019b, p. xii). This definition refers to any food that is discarded, incinerated or otherwise disposed of along the food supply chain from harvest/slaughter/catch up to, but not including, the retail level, and does not re-enter in any other productive utilization, such as feed or seed. There are some differences between the definitions used earlier by the FAO (FAO, 2011) and the definitions used in the framework of the United Nations' Sustainable Development Goals, including the Food Loss and Food Waste indices. The 2011 FAO study considered all non-food uses (feed, seed and industrial use) as loss or waste, whereas the newer SDG framework (including the FLI and FWI) does not. Furthermore, the 2011 FAO study only considered the edible parts of food, while the SDG framework considers each commodity as a whole, both edible and inedible parts. The FLI definition (as part of the SDG framework) is applied in this paper, and therefore food loss is related to 'harvest and post-harvest operations', 'post-harvest handling and storage' and 'processing and packaging'. The focus in this particular paper is on food loss, since in LMICs the largest share of total FLW in food supply chains occurs at the beginning (Brian Lipinski et al., 2013, 2017). The retail and household stages, covered by the Food Waste Index, are not explicitly focused on. The definitions of the SDG framework (marked "SDG") and the earlier definition used by FAO (marked "2011") are visualized in Figure 1.

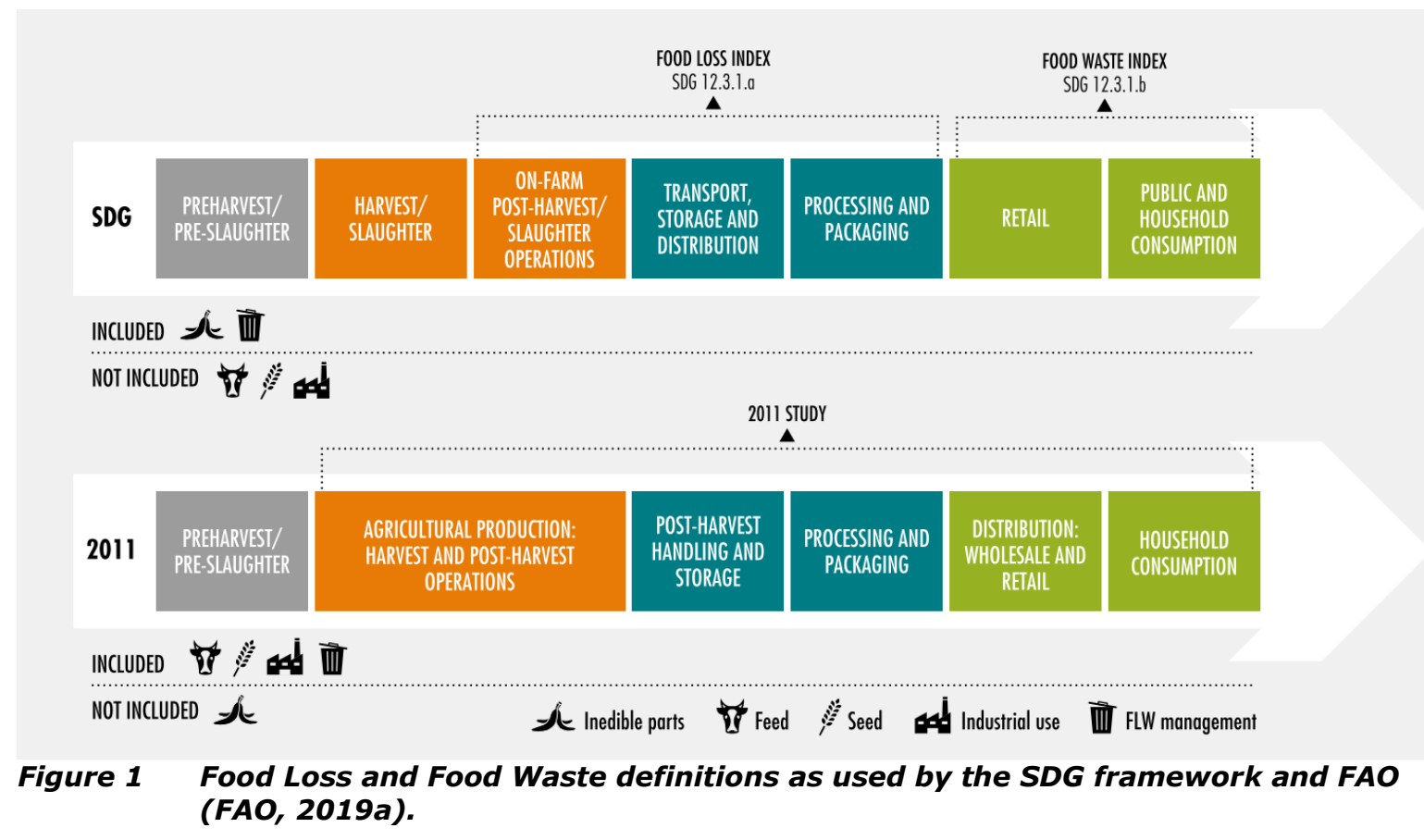


In this paper we use the definitions provided by the Food Loss and Food Waste indices, with a focus on food losses. The FLI is an estimation of how much food is lost in production or in the supply chain before it reaches the retail level (FAO, 2019a), based on loss percentages (not on volumes). The FLI focuses on the top ten commodities by economic value (per country) within the product groups of cereals and pulses, fruits and vegetables, roots, tubers and oil-bearing crops, animal products, and fish and fish products. Initial calculations of this index estimate that globally $13.8 \%$ of the world's food produced in 2016 was lost before reaching the retail level (FAO, 2019a) but huge differences exist between countries and food categories. In particular, FLI estimates of the percentage of food that is lost range from 5-6\% in Australia and New Zealand to $20-21 \%$ in Central and Southern Asia. In terms of food groups, the index shows that - worldwide - perishable products are characterized by the highest levels of FLW: roots, tubers, and oil-bearing crops report the highest level of loss, mainly driven by cassava and potato losses, followed by fruits and vegetables. One should observe that the FLI is still a rough estimate of food losses, based on a limited selection of commodities.

This paper is structured as follows. Section 2 outlines the context of food losses in LMICs. Subsequently section 3 presents an overview of food loss-reducing interventions from a comprehensive literature search, and proposes a classification approach based on several intervention characteristics. Based on this classification, we propose an evaluation approach that helps select the appropriate intervention for a given situation, based on the match between intervention characteristics and contextual factors. Section 4 presents four case studies in which the evaluative approach is applied to specific cases of food loss-reducing interventions. Section 5 contains the main conclusions. 


\section{The context: food losses in LMICs}

Implementing food loss-reducing interventions makes sense if the expected impact of such an intervention is high in the context of food loss reduction. Therefore, an evaluation of whether a given intervention can feasibly be applied in a given context - and what impact can be expected - is necessary. However, in the context of FLW literature this is a complex matter. The main issues are:

- Data reliability and comparability:

- What indicator is used to define 'high' impact? Is it \%, absolute weight or value, quality loss, etc.? And compared to what baseline?

- Data on FLW is collected with diverse methodologies, definitions and selected indicators, which makes them difficult to compare.

- The definition of FLW differs a lot in literature (see section 1), again implying less comparability.

- The reliability of available data is low because many studies use secondary data from literature rather than real measurements, and often reported measurements are hard to trace back to the source. And in case of real measurements, in most cases it is a one-point statistic. Hence, the reliability of these data is low.

- Data availability:

- The coverage of FLW data in LMICs is not equally distributed across food categories. How to evaluate 'high' impact and prioritize food products and supply chain stages for intervention analysis if data are scarce or absent for some categories?

- Similarly, the distribution of FLW data along the supply chain is skewed. Especially food loss studies tend to focus on farmers, with very limited attention for other actors in the postharvest chain.

- To evaluate interventions, selected case studies should include 'before' and 'after' food loss data. This specific data - indispensable to evaluate the effectiveness of an intervention - is scarce.

As a consequence, standardization in FLW monitoring is advised, however still not the reality of today. For evaluation, selection and design of interventions this is also a challenge - as information about the location, magnitude, and drivers of food loss in specific chains is limited. Nevertheless, for this approach to implementing food loss-reducing interventions, we accept these limitations and work with the information that is available about the intervention itself and the implementation context.

The target area for this research is Low and Middle Income Countries (LMICs), mostly located in Africa and Asia. In the Introduction section, problems related to food loss information and the structure of the food system in these regions were discussed. In sum, agricultural production in these countries is fragmented, with a dominance of smallholder farmers, with weak linkages to the main markets. Food value chains are fragmented and fluid, with very limited information being available about the location, magnitude and drivers of losses. From the information that is available we know what the agricultural production looks like, and that food losses are relatively high in early stages of these chains. Based on this, we can indicate which product categories and value chains are more relevant to consider for food loss reducing interventions.

To identify the top 10 crops and top 10 animal products respectively (by production volume), FAOSTAT is used (Table 1). In this paper 'high relevance' of a crop is interpreted as both being a major crop in terms of production volume as well as a crop suffering from significant loss percentages. 
Table 1 Production in 2017 of top 10 crops and 10 animal products in LMICs Africa and Asia; fish data are from 2013 (FAO, 2020).

\begin{tabular}{|c|c|c|c|c|c|c|}
\hline $\begin{array}{l}\text { Rank } \\
(2017)\end{array}$ & Crop name & $\begin{array}{l}\text { Production } \\
\text { (106 tons) }\end{array}$ & $\begin{array}{l}\text { \% in crop } \\
\text { production }\end{array}$ & Animal product name & $\begin{array}{l}\text { Production } \\
\text { (106 tons) }\end{array}$ & $\begin{array}{l}\% \text { in animal } \\
\text { production }\end{array}$ \\
\hline 1 & Sugar cane & 446 & $21.7 \%$ & Milk, whole fresh cow & 130 & $40.3 \%$ \\
\hline 2 & Rice, paddy & 307 & $14.9 \%$ & Milk, whole fresh buffalo & 115 & $35.7 \%$ \\
\hline$\underline{3}$ & Cassava & 194 & $9.4 \%$ & Milk, whole fresh goat & 13 & $4.0 \%$ \\
\hline 4 & Wheat & 141 & $6.8 \%$ & Freshwater Fish & 12 & $3.9 \%$ \\
\hline 5 & Maize & 106 & $5.2 \%$ & Eggs, hen, in shell & 9 & $2.6 \%$ \\
\hline 6 & Potatoes & 80 & $3.9 \%$ & Meat, chicken & 8 & $2.6 \%$ \\
\hline \multirow[t]{2}{*}{7} & Yams & 71 & $3.4 \%$ & Meat, cattle & 7 & $2.3 \%$ \\
\hline & $\begin{array}{l}\text { Vegetables, fresh } \\
\text { nes }\end{array}$ & 66 & $3.2 \%$ & Marine Fish, Other & 3 & $1.1 \%$ \\
\hline$\underline{9}$ & Bananas & 52 & $2.5 \%$ & Milk, whole fresh sheep & 3 & $1.0 \%$ \\
\hline \multirow[t]{2}{*}{10} & Onions, dry & 34 & $1.7 \%$ & Meat, pig & 3 & $0.9 \%$ \\
\hline & Total top 10 & 1498 & $72.7 \%$ & Total top 10 & 304 & $94.4 \%$ \\
\hline
\end{tabular}

Food loss data are scattered across many studies in scientific and professional literature. There are two reviewing articles providing meta-analyses of research results on food loss including the targeted regions: Affognon et al. (Affognon et al., 2015) about Sub-Saharan Africa and Xue et al. (2017) for Asia and Africa (among other regions). By comparing more studies, the reliability of the food loss estimate increases, underpinning the choice for certain products to investigate in more detail. Therefore, not only the food loss is considered but also the number of reviewed articles providing the mean result for it. Combining the meta-analyses with respect to articles on the specific region and weighing the food loss percentage according to the number of articles produces Table 2 (both metaanalyses contain a number of articles on a certain commodity, that lead to a certain average per meta-analysis, which are weighted by these numbers of articles per meta-analysis to calculate the results):

Table 2 Food loss \% for selected crops in African and Asian LMICs, based on Affognon et al. (Affognon et al., 2015) and Xue et al. (2017) (calculations by author).

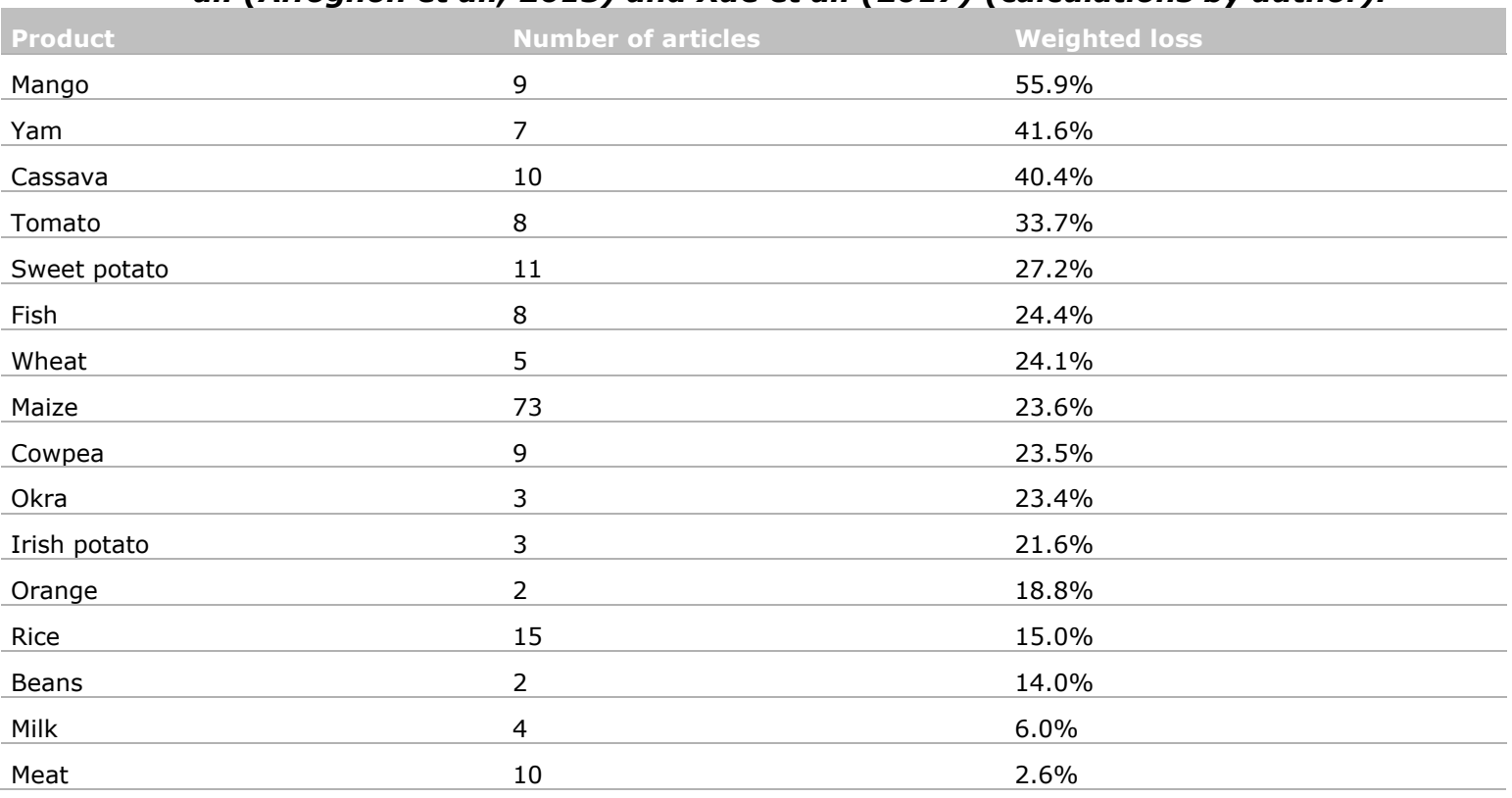

Note that the most recent articles studied in these meta-analyses are from 2015, and much more research has been done on interventions in the last few years, as shown in the next paragraph. However, the aim of this paper is not to provide an accurate update of the latest food loss statistics but rather motivate what products are relevant in the context of intervention analysis.

Table 2, together with the available examples of food loss-reducing interventions motivated the selection of the case studies. 


\section{Food loss reduction interventions categorization}

Before roughly 2015 (the year the SDGs were adopted), research tended to focus on measuring and monitoring FLW to identify FLW hot spots in terms of products and parts of the supply chain. In the last years, attention has shifted to FLW-reducing interventions to actually reach that SDG Target 12.3. Attempts for setting up interventions for reducing FLW at different levels in LMIC have already been established by different organizations such as FAO, World Bank, ADB, AfDB, Rockefeller Foundation, and the EU. For example, recently the Rockefeller Foundation released a report which presented ten different interventions to scale impact and reduce FLW (Hanson et al., 2019).

Similar to existing reviews and meta-analyses on FLW measurements, a comprehensive overview regarding interventions is desirable. This study is not a full review of interventions and their impact, but proposes a framework of how interventions can be characterized, and subsequently evaluated and selected in a way that ensures selection of an intervention that is appropriate for the context of implementation and maximizes its chance of success. Based on earlier literature, a structure is presented to categorize interventions (Table 3). As indicated before, this research primarily focuses on food loss - notwithstanding that the approach of intervention characterization, evaluation and selection can be extended to food waste interventions easily.

This categorization is based on three aspects of food loss-reducing interventions, namely the level at which it is implemented, the actors involved in or affected by the implementation, and the type of intervention (Table 3).

\begin{tabular}{lll} 
Table 3 & $\begin{array}{c}\text { Categorization of food loss-reducing interventions (author, based on literature } \\
\text { in text and Fattibene et } \mathbf{a l .}(\mathbf{2 0 2 0}) \text { ). }\end{array}$ & Type \\
\hline Level & Actors & Technology \\
\hline Micro & Farmers (smallholders) & Investment \\
\hline Meso & Governments & Good practices \\
\hline Macro & Educational programs & Organization \\
\hline & Facilitators & Policy \\
\hline & Innovators & Economics \\
\hline & Intermediaries & \\
\hline & Retailers & \\
\hline & Financiers & \\
\hline & Researchers & \\
\hline & Civil Society & \\
\hline & Processors and manufacturers \\
\hline & Packaging providers \\
\hline
\end{tabular}

\subsection{The intervention level}

Regarding the level of interventions, HLPE (HLPE, 2014) introduced a three-level structure that on the one hand unravels the hierarchy of the causes for FLW and on the other hand clarifies the manifest relations between food loss causes at various levels. The structure consists of the micro, meso and macro level, that are defined in figure 2 below: 
1. Micro level: Each particular stage of the food chain, where FLW occurs, from production to consumption, that acts in response (or not) to external factors.

2. Meso level: The level where internal actors (at the same or another stage) in the food supply chain or external stakeholders, impact the FLW on micro level as a result of how different actors are organized together or related to one another, or of the state of infrastructure (e.g. storage) in the context of the relation.

3. Macro level: Here FLW is explained by more systematic issues, such as malfunctioning food systems, lack of institutional or policy conditions to facilitate the coordination of actors, to enable investments and adoption of good practices.

Figure 2 Definition of the different levels of FL-reducing interventions. Based on HLPE (2014).

These definitions were introduced by HLPE (HLPE, 2014) to structure the causes of FLW, but also to structure the solutions to reduce FLW - i.e. FLW-reducing interventions. This structure facilitates the logical mapping of causes, solutions, and actors that should be involved, and recognizes the cascade effects that dynamics at one level can also affect other levels. Roughly speaking, the micro level is about issues that concern one or two individual links in a particular food supply chain. For example, an intervention that aims at improving handling of the food product on the farm to reduce food loss is considered an intervention at the micro level. On the meso level, interventions take place in a relationship that is not one-on-one, but involves larger groups and different stakeholders in the food chain. The intervention is applicable across a larger part of the supply chain or affects multiple supply chains. For example, training and education of groups of farmers by local extension officers on postharvest practices can be considered a meso-level intervention. The macro level is typically a type of intervention implemented by the (local or national) government. Interventions to extend the network of paved roads, tax-reduction measures for certain technologies, or facilitation of extension services with content, material and finance are all examples of macro level interventions which involves governmental bodies, affecting the entire supply chain, an entire region and/or an entire group of actors. Setting national FLW reduction strategies and public-private partnerships that involve many supply chain stakeholders are also considered macro level interventions.

In many cases, interactions happen between the different levels. For example, when on the micro level, knowledge or significant financial resources are required, interventions at meso and macro levels at the same time are usually needed. Moreover, the best supply chain stage and level at which to intervene depends on the intervention objective and aspects of the (regional) context, and needs to be evaluated for each case. For example: on the micro level FLW results from poor handling on the farm. If farmers have no education or training, no FLW reduction can be achieved. This can be solved on the meso level by local extension officers giving training to a farmers in a region. On the other hand, these extension officers need to be facilitated with content, material and finance, which is a macro level issue for governmental bodies or private investors, involving programs at a larger scale.

\subsection{The intervention actors}

The other key element in a food loss intervention is the actors of the supply chain that will be involved in the reduction strategy. A list of possible actors is presented in Table 3 and depends on the type and level of the intervention. The actors involved depend as well on whether the food loss intervention is on-farm, including all the actions and improvements on for example curing, drying and storage of food products at the farm level, or if it is off-farm, when crops or perishable products leave the farm to be processed, stored, packed or transported to reach the market. Smallholders are one of the main actors that should be involved in on-farm food loss interventions, since in LMIC, smallholder farmers are the main food producers: $80 \%$ of African farms are under 2 ha in size (Vanlauwe et al., 2014). Smallholding has been defined by FAO as "an agricultural holding run by a family using mostly (or only) their own labor and deriving from that work a large but variable share of its income, in kind or in cash" (Khalil et al., 2017). Smallholders are not a homogeneous group but rather a diverse set of households with varying farm and household characteristics. (Manual) labor-intensity is a key feature of smallholder agriculture, which relies on family labor or labor exchanges within the neighborhood and with limited reliance on temporary hired labor. Smallholder farming is also characterized by mixed farming systems often including various food and cash crops and livestock. 
Smallholders often have limited resources in terms of assets or capital (human, natural, social, physical, and financial), with smallholders often being barely able to sustain an acceptable livelihood and with very little margin for seizing their development opportunities. Smallholders are principally family farmers and it is important to note that smallholder agriculture is not by definition equivalent to poverty.

Correct management of food products in the first phases after harvesting can have a great impact on PHL by extending product shelf life. This in turn can affect well-being of smallholders who can be disadvantaged by losses both on the farm and beyond the farm gate. However, it cannot be expected that smallholders alone will be able to design and implement food loss interventions. For example, in the publication by Flanagan et al. (2019) key characteristics of cases where PHL would be minimized are identified. These involve promoting access to low-cost technologies, to improved knowledge and skills in harvesting and storage, and to small-scale appropriate financing to support usage of technologies. Each of these characteristics requires involvement of actors in addition to the individual smallholder farmer, including educators and programs for training, governments for tailored policies to support smallholders, technology providers and innovators, financial service providers, and intermediaries to provide low-cost technologies.

\subsection{The intervention types}

The authors propose a categorization that divides food loss-reducing interventions in 6 different types:

1) Technology - Physical tools or equipment

2) Finance \& investment - Funding, credit, insurance and other financial products and services

3) Best Practices - Changing processes or practices based on knowledge of how to reduce FLW

4) Organization - Coordination inside food chains

5) Policy - Government policy affecting the incentive structure and enabling environment

6) Economics - Markets and market linkages, economic decision-making

In the section below, an overview per category is presented of interventions found through a literature survey, showing how they can be mapped on the framework with the type and level of interventions and the actors. This overview focuses on interventions implemented in LMIC: countries with relatively high food losses early on in the chain and food supply chains with fragmented production (smallholder farmers in remote areas) and weak linkages. Food loss-reducing interventions in LMIC should fit the context of smallholder farmers with limited resources and capabilities, and are therefore skewed towards low- and mid-tech interventions. This highlights the core of the purpose of the approach in this study: evaluating which interventions best fit the food system, given all relevant aspects of the food system context. The list was obtained through a search of main scholarly databases using various search terms related to the topic (e.g. 'food loss', 'postharvest', 'postharvest loss', 'farming' etc.). It should be noted that the aim of this study is not a complete and exhaustive overview including any and all niche solutions, but rather to show how the categorization proposed can help evaluate and select possible strategies from a selection of widely used interventions. Nor are the types mutually exclusive: interventions may involve elements of different types (e.g. technology being introduced, accompanied with training on best practices). In fact, successful intervention strategies often address multiple causes of food losses: solving only one cause may not be enough to reduce food loss, but a combination of factors may lie at the root of the problem, requiring a combination of interventions. Moreover, the categorization used here - though following similar frameworks from literature (HLPE, 2014; Stathers et al., 2020) - is not set in stone, with alternatives being possible.

\subsubsection{Technology}

Many solutions to reduce food loss relate to technological interventions such as storage or processing technologies. These can reduce losses almost immediately and can be implemented mostly on the micro level and sometimes on the meso or macro levels. Usually, the smallholder or other (single) supply chain actor is the recipient and user of the technology, which in turn is developed by innovators and distributed through intermediaries. 
Most of these are on-farm interventions, but some technologies can also be implemented in later stages of the supply chain and prevent losses or help retain the quality of the food products.

Technology interventions are aimed at different stages of the post-harvest system including storage, (pre)cooling, processing, packaging and transportation. Technology interventions can also improve products' traceability and facilitate communication among farmers and other stakeholders. Examples found in literature are provided in Table 4:

\section{Table 4 Technology-type food loss interventions. For sources, see rightmost column.}

\begin{tabular}{|c|c|c|c|}
\hline Technology & Examples & Level & Ref \\
\hline \multirow[t]{4}{*}{ Storage } & $\begin{array}{l}\text { Small scale: Zero Energy Cold Chambers (ZECC), Underground } \\
\text { storage (root cellars) (non-mechanical), Coolbot Cold rooms } \\
\text { (mechanical) } \\
\text { Large scale: evaporatively cooled warehouses (non-mechanical), } \\
\text { Controlled Atmosphere (mechanical) }\end{array}$ & 1 & $\begin{array}{l}\text { (Global Knowledge Initiative, } \\
\text { 2014; HLPE, 2014; Kimiywe, } \\
\text { 2015; Kitinoja, 2013; Lassen } \\
\text { et al., 2020; Sibomana et al., } \\
\text { 2016) }\end{array}$ \\
\hline & $\begin{array}{l}\text { Bags/smaller units: Metallic silos, Purdue Improved Crop Storage } \\
\text { bags (PICS), antiseptic bags, cloth shade structure) }\end{array}$ & 1 & $\begin{array}{l}\text { (Affognon et al., 2014; } \\
\text { Global Knowledge Initiative, } \\
\text { 2014; HLPE, 2014; Kimiywe, } \\
\text { 2015; Viola, 2017) }\end{array}$ \\
\hline & Wooden or plastic crates for fish storage & 1 & (Akande \& Diei-Ouadi, 2010) \\
\hline & Family-based storage from local materials & 1 & $\begin{array}{l}\text { (Global Knowledge Initiative, } \\
\text { 2014) }\end{array}$ \\
\hline \multirow[t]{2}{*}{ (Pre)cooling } & $\begin{array}{l}\text { Small scale: Portable forced air cooling systems (mechanical), } \\
\text { Portable evaporative forced air cooling systems (non-mechanical) } \\
\text { Large scale: Vacuum cooling, Forced air cooling, Hydro-cooling } \\
\text { (all mechanical), slurry ice (non-mechanical) } \\
\text { Low-cost portable hydro coolers }\end{array}$ & 1 & $\begin{array}{l}\text { (Akande \& Diei-Ouadi, 2010; } \\
\text { HLPE, 2014; Kitinoja, 2013; } \\
\text { Odoli et al., 2018; Owino, } \\
\text { 2013) }\end{array}$ \\
\hline & Temperature management (differentiate per product) & 1 & $($ COMCEC, 2016) \\
\hline \multirow[t]{5}{*}{ Processing } & $\begin{array}{l}\text { Drying (solar, mechanical, mobile, maize crib elevated on poles, } \\
\text { avoid contact with the soil) }\end{array}$ & 1 & $\begin{array}{l}\text { (Akande \& Diei-Ouadi, 2010; } \\
\text { COMCEC, 2016; Costa, 2014; } \\
\text { Global Knowledge Initiative, } \\
\text { 2014; HLPE, 2014; Kimiywe, } \\
\text { 2015; Odoli et al., 2018; } \\
\text { Owino, 2013) }\end{array}$ \\
\hline & Canning & 1 & (Kimiywe, 2015) \\
\hline & Salting and smoking (animal products) & 1 & (Kimiywe, 2015) \\
\hline & $\begin{array}{l}\text { Creating new products (condiments, jam, pulping, juicing, flour, } \\
\text { Super Gari (cassava)) }\end{array}$ & 1 & $\begin{array}{l}\text { (Global Knowledge Initiative, } \\
\text { 2014; Kimiywe, 2015) }\end{array}$ \\
\hline & Small scale tomato paste processing systems & 1 & (Owino, 2013) \\
\hline \multirow[t]{4}{*}{ Packaging } & Modified Atmosphere Packaging & 1 & $\begin{array}{l}\text { (Kimiywe, 2015; Sibomana } \\
\text { et al., 2016) }\end{array}$ \\
\hline & Plastic crates & 1 & $\begin{array}{l}\text { (Global Knowledge Initiative, } \\
\text { 2014; Sibomana et al., } \\
\text { 2016) }\end{array}$ \\
\hline & $\begin{array}{l}\text { Use edible coating to mimic Modified Atmosphere (locally sourced } \\
\text { inputs) }\end{array}$ & 1 & $\begin{array}{l}\text { (Global Knowledge Initiative, } \\
\text { 2014) }\end{array}$ \\
\hline & Use micro-perforated plastic films to extend high quality period & 1 & (Sibomana et al., 2016) \\
\hline \multirow[t]{4}{*}{ Communication } & Cell phone to improve quality and lead time of market information & 1 & $\begin{array}{l}\text { (Affognon et al., 2014; } \\
\text { Akande \& Diei-Ouadi, 2010; } \\
\text { Odoli et al., 2018) }\end{array}$ \\
\hline & Training on internet communication & 2 & $($ COMCEC, 2016) \\
\hline & Provide weather data via satellites & 3 & $\begin{array}{l}\text { (Global Knowledge Initiative, } \\
\text { 2014) }\end{array}$ \\
\hline & $\begin{array}{l}\text { Electronic payment system, creating market linkage, risk } \\
\text { reduction }\end{array}$ & 1 & $\begin{array}{l}\text { (Global Knowledge Initiative, } \\
\text { 2014) }\end{array}$ \\
\hline $\begin{array}{l}\text { Cooled } \\
\text { transport }\end{array}$ & $\begin{array}{l}\text { Small scale: USDA Porta-cooler } \\
\text { Large scale: cooled trucks, reefers(mechanical), Passive cooling } \\
\text { (insulated pallet covers) (non-mechanical) }\end{array}$ & 1 & (Kitinoja, 2013) \\
\hline
\end{tabular}




\begin{tabular}{llll}
\hline & & & \\
& Transport at night & 1 & (Widyastuti et al., 2017) \\
\cline { 2 - 4 } & Streamline the value chain to decrease delays in transport & 2 & (COMCEC, 2016) \\
\hline Traceability & $\begin{array}{l}\text { Set up "first mile" quality enhancement from farmer to first } \\
\text { aggregation point to strengthen the partnership between farmers }\end{array}$ & 1 & (Global Knowledge Initiative, \\
& and processors or exporters & & \\
\hline
\end{tabular}

While the critical role of cold chains to ensure dietary quality from a food safety and food availability perspective is recognized (e.g. HLPE (HLPE, 2014), this kind of intervention is not always recommended in LMIC. Large and expensive infrastructure may not always be the best option for smallholders, lowering the chances of interventions' successful adoption. It is therefore important that an intervention is implemented with the right level of technology, appropriate for the context and complexities of the targeted food system. For example, low and mid-tech solutions may be a better fit for smallholder farmers and other small- and medium-sized enterprises (SMEs) in LMIC than more expensive high-tech interventions (Trienekens, 2011). This is based on the high cost price (and often more expensive maintenance needs) of high-tech interventions, relative to the limited purchasing power of stakeholders in LMIC contexts, and because low and mid-tech solutions are more likely to be compatible with local knowledge, capabilities, infrastructure, and current practices.

\subsubsection{Finance and investment}

Economic investment is required to implement interventions like technologies or training/extension services. Smallholders do not have the means for it and depend on the - often limited - local financial system for access to credit, insurance, and other financial services. When smallholder farmers can have access to a wider range of financial service providers, intermediaries, and services, they can more easily obtain a product or service that suits their needs. Examples can include government credits, microfinance provision, but also local credit associations. Hence interventions with respect to investment facilitation are of meso and/or macro level. An example is a farmer that can receive credit to connect to export chains if he is performing according to certification and standards, based on training initiated by an exporter.

\section{Table 5 Finance- and investment-type food loss interventions. For sources, see} rightmost column.

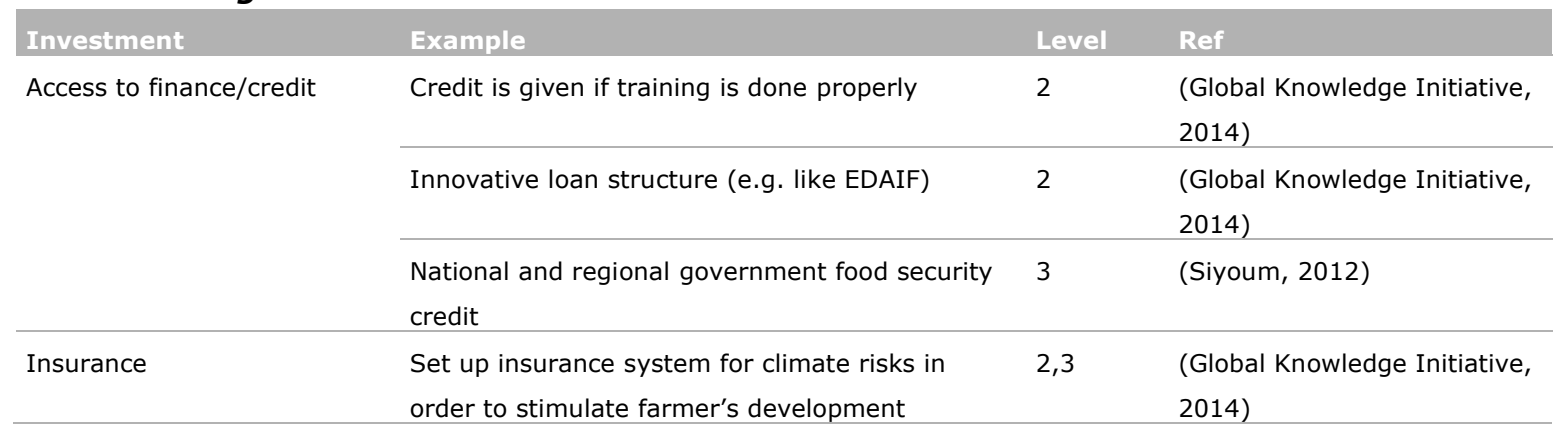

\subsubsection{Best practices}

FLW might be reduced significantly if knowledge on proper practices in production, harvesting, processing and other food chain activities is made available to smallholders in a sustainable way. Most relevant knowledge to reduce FLW can be described as best practices. Training and educational programs could help the spread of this knowledge together with knowledge sharing through farmers' communities and cooperatives. Table 6 shows examples of effective best practices to reduce food losses. 
Table 6 Best practices for product handling as a type of food loss interventions. For
sources, see rightmost column.

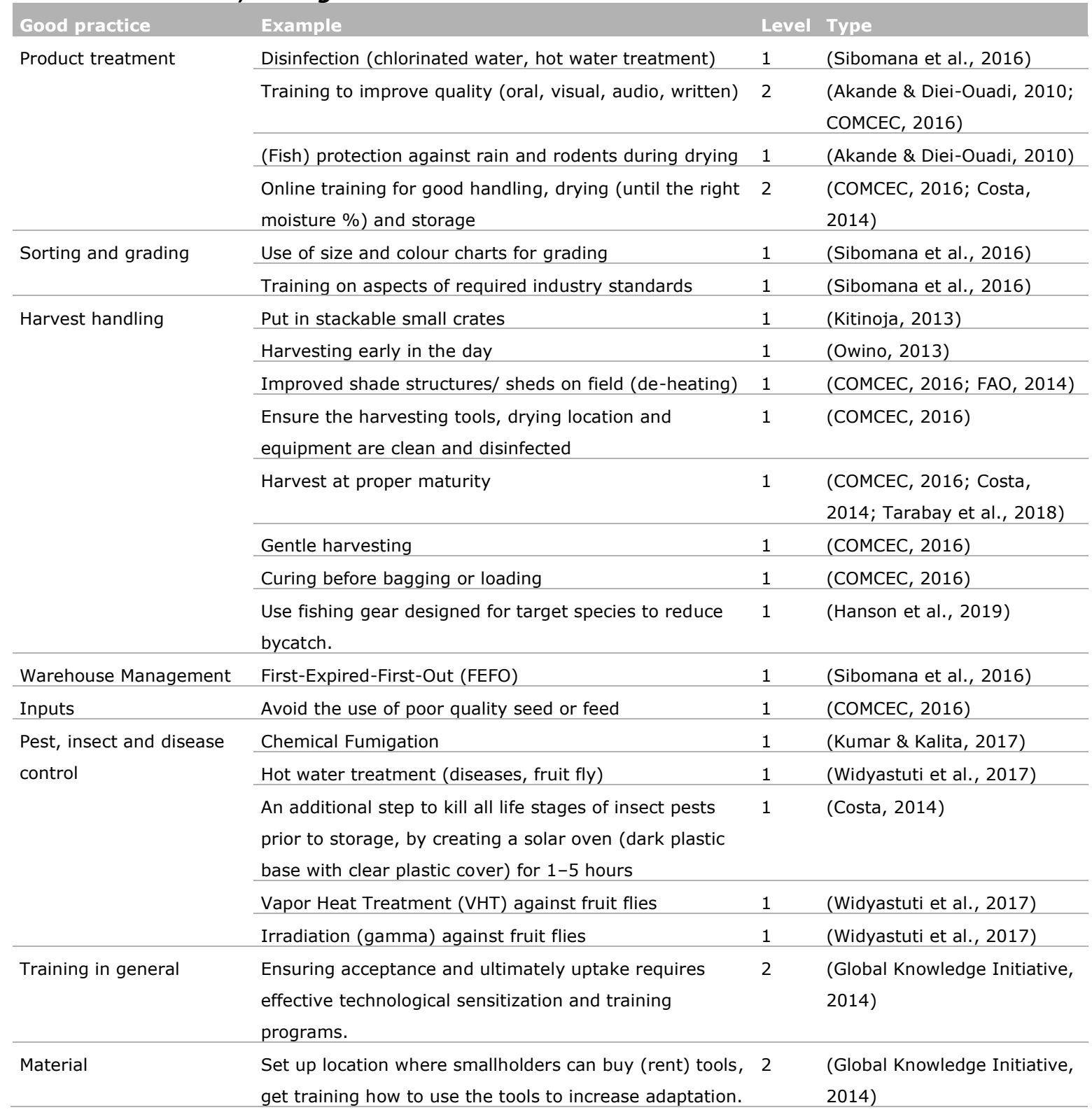

\subsubsection{Organization}

Food loss-reducing interventions rarely target only single smallholders, since upgrading only one smallholder farm is not a feasible business case. Interventions in most cases need economies of scale to increase the product volume and improve performance in the context of a specific market (not necessarily high-end). Therefore, organizing farmers in some way (connecting to collection centers, to one client (such as a processor or exporter), or for training purposes, etc.) is a logical step to facilitate interventions. Nevertheless, successfully organizing farmers over a long period of time has proven complicated as many factors such as market conditions, production and supply from producers, and trust play a role. Table 7 shows examples of potentially food loss-reducing interventions that often require producer organization. 
Table 7 Organization-type food loss interventions. For sources, see rightmost column.

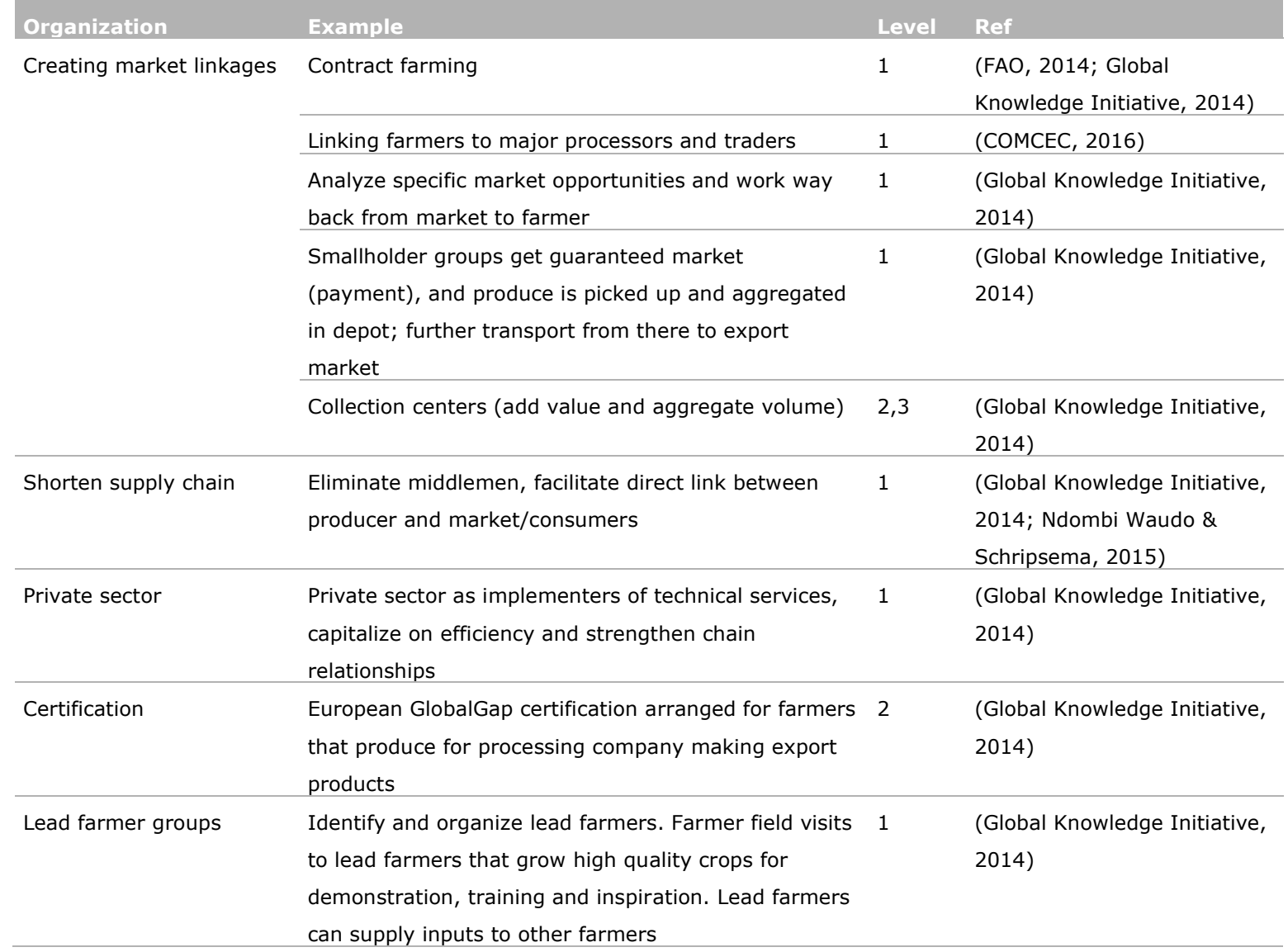

\subsubsection{Policy}

Regional, national, and international policies impact on agricultural value chains in various ways by having an effect on import and export regulations, fiscal issues, food safety, trade regulations, food security, environmental aspects and social protection. Higher level policy can also drive food loss reduction, for example in relation to physical (e.g. roads) and communications (e.g. cellular network) infrastructure. These high level interventions in most cases are not implemented with the specific aim of reducing food losses. Nevertheless, their potential impact on food loss reduction is high, since smallholder's possibilities in terms of market access and information provision can improve significantly.

Table 8 Policy-type food loss interventions. For sources, see rightmost column.

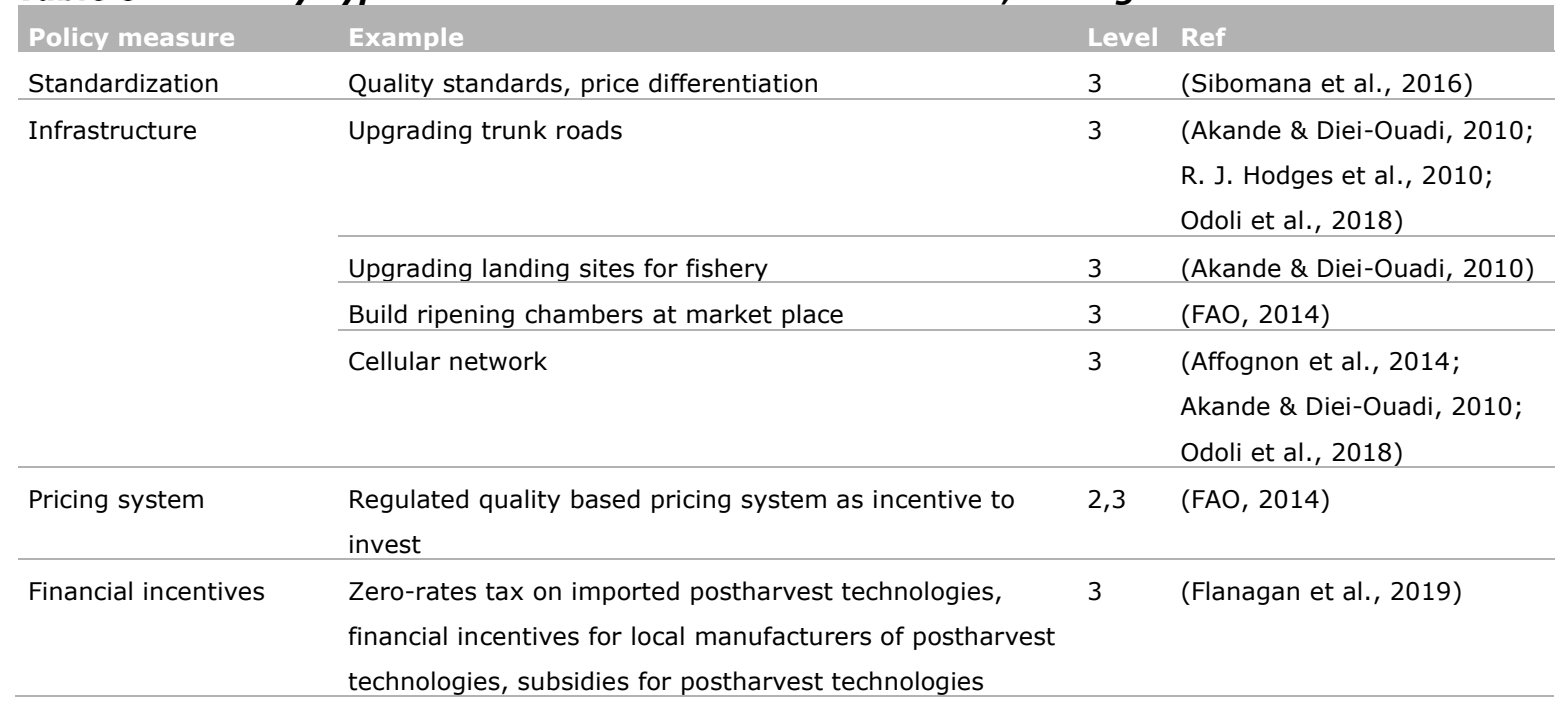




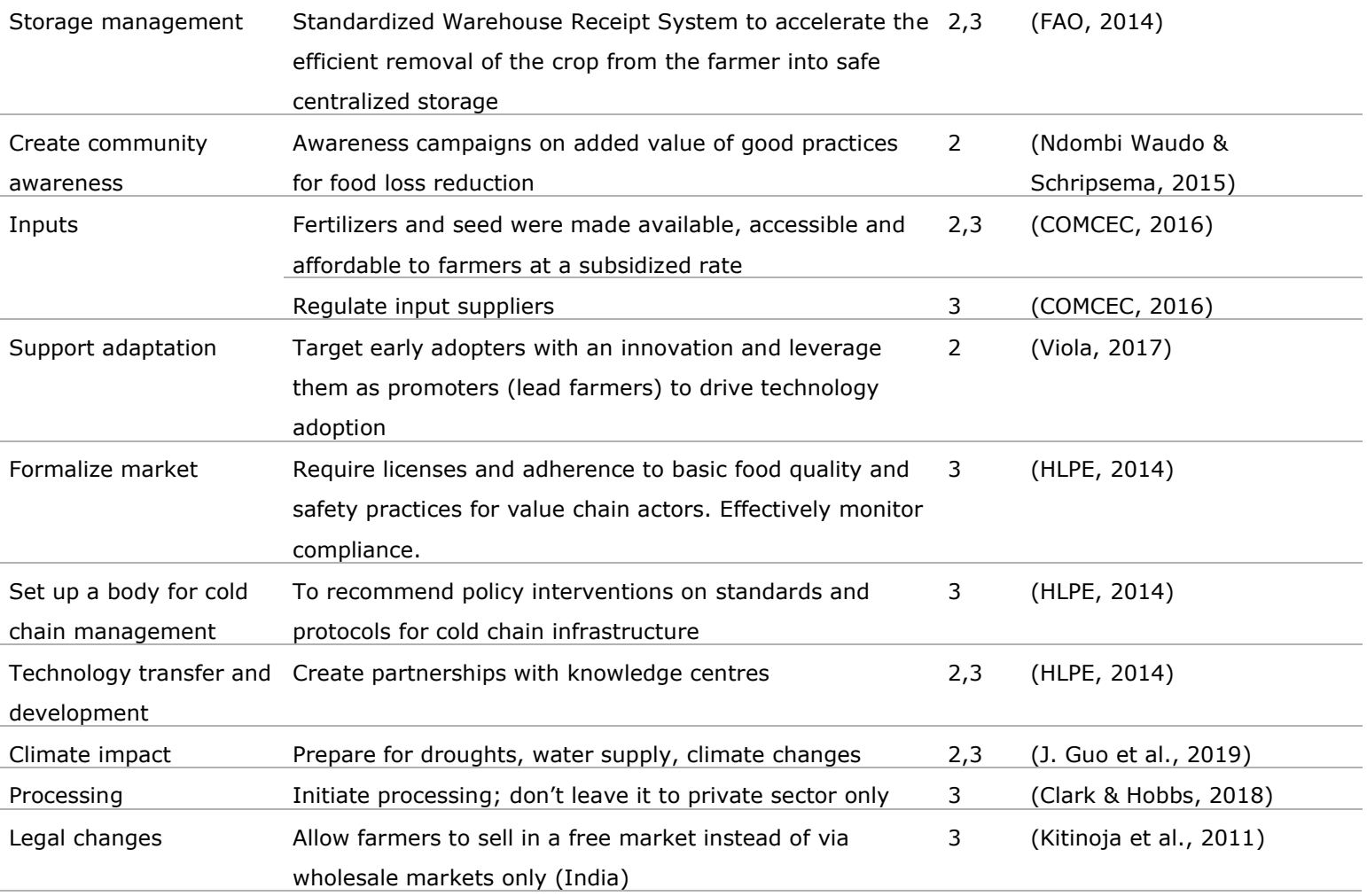

\subsubsection{Economics}

For successful implementation of food loss-reducing interventions it is important that producers have economically healthy businesses, and that they are supported in managing their income and credit and in the process of planning and making (small) investments. To do so it is essential to have access to market information, to understand market processes and to know market requirements. For example, farmers can invest in (more expensive) crop varieties with higher yields and/or less disease sensitivity. This does require a feasibility check, that enables the smallholder to make well-founded decisions in product and variety selection. To make the shift to this type of decision-making, farmers need to be educated on all relevant aspects of these business decisions (the market, their options for improvement, insight in their own farming operation, insight in costs and benefits etc.) and be facilitated in accessing the financial services needed (savings, credit, insurance). Hence, regarding this type of intervention, not only the farmers are involved, but there is also a role for other actors such as policymakers, input providers, and financial service providers.

Table 9 Economics-type food loss interventions. For sources, see rightmost column.

\begin{tabular}{|c|c|c|c|}
\hline Economics & Example & Level & Ref \\
\hline Standardization & $\begin{array}{l}\text { Quality standards, price differentiation, offering price } \\
\text { incentives for quality }\end{array}$ & 2 & $\begin{array}{l}\text { (HLPE, 2014; Kitinoja et al., } \\
\text { 2011) }\end{array}$ \\
\hline \multirow[t]{3}{*}{$\begin{array}{l}\text { Freedom and choice of } \\
\text { variety }\end{array}$} & Provision of clean and certified variety & 2,3 & $\begin{array}{l}\text { (Ndombi Waudo \& } \\
\text { Schripsema, 2015) }\end{array}$ \\
\hline & Adapt varieties to different market (preferences) & 2,3 & (Owino, 2013) \\
\hline & Deployment of insect resistance varieties & 2 & (Tefera et al., 2016) \\
\hline Food loss measurement & $\begin{array}{l}\text { Train farmer to carry out costs analysis on food loss and } \\
\text { (simple) intervention }\end{array}$ & 1,2 & $\begin{array}{l}\text { (Ndombi Waudo \& } \\
\text { Schripsema, 2015) }\end{array}$ \\
\hline Entrepreneurship & $\begin{array}{l}\text { Training on credit management, banking culture, human } \\
\text { resource management, record keeping }\end{array}$ & 2,3 & $\begin{array}{l}\text { (Global Knowledge Initiative, } \\
\text { 2014) }\end{array}$ \\
\hline Trade agreement & $\begin{array}{l}\text { Warrant system: It is a quasi-financial arrangement that } \\
\text { allows farmers to "save" grains in a grain-trading } \\
\text { company and farmers have the ownership of the grain } \\
\text { while the company has the use right. Then the company } \\
\text { earns profits by trading grains and part of that profit is } \\
\text { returned to farmers as "interest". }\end{array}$ & 2,3 & (HLPE, 2014) \\
\hline
\end{tabular}




\subsection{Intervention evaluation}

The section above shows the diversity of interventions that can be implemented to reduce food losses, at different levels and of different types. Governments, development agencies, NGOs and private companies are keen on investing in solutions to improve supply chains and reduce food losses. However, 50 - $64 \%$ of value chain development projects in developing countries fail (Ika, 2019). This highlights the necessity of intervention evaluation: a process to understand an intervention, how it has been implemented, what effects it had, for whom, how and why. An evaluation examines how an intervention was designed, carried out, and what the results of the intervention were. Therefore, evaluations are focused on practice and investigate what has happened in practice, rather than what was expected to happen. Important elements of intervention evaluation include quantification of food loss reduction, sustainability assessment, and the adoption rate. Numerous implementations in less developed countries are paid by donor programs, however a priori evaluation of the adoption rate often focuses on (expected) economic impact and affordability only, whereas many other aspects may cause the refusal of actors to get involved in the first place. A few examples of causes of adoption failure are (Adegbola, 2010; Ika, 2019):

- Inadequate beneficiary needs analysis: Most projects suffer from lack of ownership. The projects do not address the needs of the people. The projects can be inadequately adapted to the context of the beneficiary.

- Poor stakeholder management, interventions to reduce PHL are developed and tested with insufficient local stakeholder participation.

- Overemphasis on technical and/or financial feasibility at the expense of social, cultural, environmental and political feasibility.

- Projects are short-term, thus not building a solid base that will allow project to work successfully with low resource communities. This includes lack of technical support once the project ends

- Different agendas among stakeholders.

- Interventions often address FLW as a purely technical challenge, and fail to take into account market dynamics and other important factors.

- Limited governmental regulation and legislation to support postharvest activities, inadequacies in policy, poor extension services and information exchange. No broader inclusion of the postharvest component in governmental projects.

- PH interventions ignore the economic feasibility. No cost and benefit analysis done prior to implementation.

- Supply chain intervention tend to ignore middlemen, traders and processor but they have an impact on the final product quality.

- Resource limitation, for most interventions some level of financial investment is required.

- Low literacy rate and technical capabilities among the beneficiaries, some interventions require continuous maintenance and some level of literacy is required to understand the operation and maintenance requirements.

- For storage innovations the misperception of the effectiveness of the intervention and of the investment costs or the reduced access to the village through the year due to road conditions have been reported as factors affecting the likelihood to abandon the storage introduced by the food loss intervention.

When planning a development intervention to reduce FLW in LMIC, particular care should be taken to not create so called 'white elephants'. As discussed in the introduction, this term refers to expensive solutions that cannot be put to useful work, and often instead impoverish the recipient with the burden of maintenance and upkeep. In development interventions in LMIC countries 'white elephants' can emerge when communities are not involved or taken in consideration in the implementation of the intervention while 'alien' technologies are imported into the community with limited compatibility with the local context (HLPE, 2014). This often results in low adoption of these solutions, especially when external economic and knowledge support stops. For example, while many biological and environmental factors that contribute to postharvest losses are known (HLPE, 2013; Vanlauwe et al., 2014) and technologies have been developed to reduce these losses, these technologies have not been implemented due to different factors like inadequate marketing systems, poor transportation facilities, poor maintenance, lack of information, education, legislation and regulation (Xue et al., 
2017). These factors - and more in general all the factors that facilitate or constrain the adoption of interventions - should be taken into account when evaluating an intervention for food loss reduction.

Success of a food loss-reducing intervention depends on performance in reducing losses and sustained adoption. The first parameter to understand if an intervention was successful is a quantitative indication of the reduction of losses along the supply chain of the product after the intervention. In this perspective, a comparison between the food loss levels before and after the intervention or by using cross-sectional data on adopters and non-adopters, is recommended. As specified before, quantification of losses along the supply chain is a complex task and different tools for this have been proposed depending on the definition of food loss and the evaluated aspects (M. Kok et al., 2021). The second parameter to evaluate the success of an intervention is the adoption rate among targeted stakeholders. While an intervention may have an outstanding performance in reducing food loss, if it is not adopted by the community or if a high rate of abandonment is observed it can hardly be classified as successful.

Evaluating the adoption rate over time is possible but is often expense in terms of both resources and time since few years have to pass. It would be much more convenient to predict or anticipate the possible adoption rate of the intervention before putting this into practice, and select interventions accordingly. In the next section we propose a list of critical success factor for the adoption of an intervention derived from different studies on adoption of development interventions.

\subsubsection{Adoption criteria for FLW reduction interventions}

Many interventions in LMIC food systems are driven by the aim for economic development, but at the same time they reduce FLW (Klink, 2015). In fact, almost every improvement of a food supply chain in the same way directly or indirectly reduces the FLW - just as effectively reducing FLW contributes to farmers' livelihoods and to food security. The focus here is on interventions, where food loss reduction is one of the main drivers. Previously we defined success in terms of an intervention resulting in a reduction in food losses and being successfully adopted to the extent that this impact can be realized.

This study introduces a framework where relations between certain criteria and post-harvest lossesrelated output indicators shine a light on the intervention adoption rate by supply chain stakeholders. Several studies report on the relationship between adoption rate and food loss-related output indicators, applying statistical analyses on farmer characteristics (which could include distance to market) (Adegbola, 2010; Owach et al., 2017). Although relevant factors were identified, the explained variances of such (simple linear) models are very low (e.g. in (Owach et al., 2017) around $20 \%$ ), indicating that the factors included explain only a small share of differences in adoption rate. Additional criteria are required to increase the predictability of adoption of interventions. After successful adoption of the intervention, its impact on food loss - and economic, social and environmental outcomes - should be evaluated. 
Literature provides suggestions for relevant criteria for successful adoption of a loss-reducing intervention. Not claiming completeness, the following criteria are a selection from (Klink, 2015; Owach et al., 2017; Shiri, 2019; Viola, 2017):

- Affordability: An intervention needs to be affordable to people with low purchasing power in LMIC markets.

- Availability (Accessibility): Availability or accessibility is the extent to which the products or services are available for immediate use with minimal complications for value chain actors. This can be challenging in LMIC markets, due to the fragmented nature or the non-existence of distribution channels.

- Acceptability: The intervention must be accepted by the wider society, which requires compatibility with the existing culture, with its social norms and values. Acceptability by value chain actors for the consumption, distribution and sales of a product or service, plays a vital role in the successful adoption of an intervention.

- Awareness: People should be made aware of the existence and benefits of the innovation to be successful. Many of the poor consumers cannot be reached by conventional advertising media, hence novel ways of reaching customers must be conceived.

- Technical feasibility: The intervention must be simple and technically feasible to implement in the context of developing countries. The technology must be durable, easily repairable and adaptable to people in developing countries, adjusted to local technical knowledge. Preferably, the technology should be developed locally.

- Adaptability: The intervention should be adaptable to suit the prevailing (and changing) environment and infrastructure.

- Scalability: The ability of an innovation to achieve widespread adoption.

- Resource availability: The necessary physical resources for the operation of the technology should be sufficiently available at local levels.

- Time to impact: Assesses both the time it will take a given initiative to show an effect as well as the durability of the impact.

- Availability of extension services: For continuity in knowledge transfer.

- Participatory approach: Evaluate whether the intervention was developed and introduced by following a participatory approach that involved local stakeholders in the decision-making process or if it was brought by third parties like non-local investors. Participatory methods can enhance the uptake and sustainable use of new (e.g. technological) solutions. The characteristics of this approach might also affect adoption rate.

The proposed criteria are likely to influence the adoption (or abandonment) rate and it is therefore critical to evaluate their presence/absence with regard to a food loss-reducing intervention. For example, if an intervention has proven to successfully reduce food losses and is also affordable, it is more likely to be adopted. Availability and affordability play a key role in the adoption of interventions that improve the food supply systems by allowing small and medium enterprises and farmers to invest in a financially sustainable way and increase production (Verschoor et al., 2020). Moreover, the proposed criteria are not independent, meaning that the presence or the absence of one of them can affect also the other criteria. For example, when a participatory approach is used to develop and implement the intervention, a higher acceptability from the community and/or stakeholders together with higher efficiency and effectiveness is expected (Plaisier et al., 2019). Moreover, the presence of an extension service can greatly affect the actors' awareness of intervention benefits. We therefore propose to include in the intervention evaluation a screening for the presence/absence of these criteria that can significantly influence intervention adoption rate.

It is important to note that the intervention adoption rate can be significantly influenced also by its context: elements such as the food product involved or the region where the intervention takes place can have an effect. For example, wheat is easier to store than milk and policies might differ per country. These elements are implicitly part of the criteria above like affordability, technical feasibility, and availability of extension services. 
Several reasons make it complex to assess the effect of these factors. In general the criteria are not independent, implying that if some level of prediction of adoption is desired, many data and thorough regression modelling are necessary. An example is the fact that when something is affordable, it is adopted more easily, making it challenging to separate the effect of the two factors. Intervention studies often only include a small subset of the criteria mentioned above, and indicators (let alone scores and ranges for a methodology) are not generated for all these criteria. In addition to the long list of potentially relevant criteria (often discrete), there is the dichotomy of the adoption outcome ('yes' or 'no'), increasing the complexity of modeling.

A last step to further increase the challenge of 'insight in adoption prediction' is including the process of introduction of an intervention. Interventions can be initiated by third parties like non-local investors, but the way the local stakeholders (in case of post-harvest losses mostly farmers) are involved in the decision making may also affect the adoption rate. A participatory approach, where several types of interventions are explained and discussed can enhance the uptake and sustainable use of new (e.g. technological) interventions (Plaisier et al., 2019). The variables involved in different implementations of this approach, like 'relation to farmers' (local extension services, scientists from abroad), 'intensity of discussion in days and/or lead time' and so on might also differentiate the adoption rate.

In this section it is shown that many issues may affect the level of adoption of an intervention in LMICs. Currently, the ultimate goal of fitting all intervention projects into an uniform explanatory model is out of reach. No intervention project provides all information one would be interested in to perform a complete evaluation, and many different cases and data sets are needed to create an acceptable level of quantitative predictability. Despite these limitations, the proposed framework will be applied in a more qualitative approach to four different case studies where different types of interventions were applied in different LMIC countries (Nigeria, Benin, and Indonesia) to reduce food losses.

\subsubsection{Food system considerations}

In addition to an intervention's effectiveness in reducing losses and the extent to which it is sustainably adopted by users, other outcomes can be considered to evaluate the broader impact of FLW reducing interventions. Examples of such outcomes originate from the food system approach (Berkum et al., 2018) - a holistic view of the food system with its production system, value chain, drivers (environmental and socio-economic) and impacts (economic, socio-economic and environmental - similar to the three pillars of sustainability). These outcomes can be included in an intervention evaluation to achieve a more comprehensive evaluation of its impact. Food losses have negative consequences for all three outcomes, and accordingly successfully addressing food losses has positive impact across these three outcomes. Ideally, a successful intervention reduces food losses, increases farmers' household income, increases the amount of food that is available for consumption, and reduces the environmental impact due to food losses.

Many interventions are driven by the aim for economic development. In post-harvest losses the direct economic impact is straightforwardly defined as the net result of on the one hand the investment and on the other hand reduction of the value of the food losses. However, often improvements in the food chain have impact in the food system beyond only qualitative and quantitative reduction of losses. This includes broadening the possibilities of smallholders, additional (and more diverse) economic activity in rural communities, and other spillover effects. When interventions introduce more income, more knowledge, and better practices in a local food system, social food system outcomes can also show improvement, for example when broadening opportunities for education and training, and empowerment of women when equitable distribution of the benefits is safeguarded. On the environmental pillar, FLW has implications for greenhouse gas emissions and water and land use, and any intervention that impacts on FLW, also (indirectly) impacts on these outcomes. For example, less GHG are emitted in the production of a certain quantity of food, and less water, land, and agricultural inputs are needed to produce the same amount - all lessening the environmental impact of the food chain. 
The question of how to effectively integrate all relevant food system outcomes in FLW-focused research is a challenging one, but based on present knowledge we can propose a way forward. Usually, in literature the impact of a food loss-reducing intervention is considered with respect to economic profit, quality increase and/or food loss reduction. However, more and more studies start to propose as well other indicators. For example, in a food systems approach (Berkum et al., 2018) a list of socio-economic and environmental indicators was derived from the food system drivers. Also, different studies investigated the relation between food loss (and waste) and its environmental impact (FAO, 2019b; X. Guo et al., 2020; Kashyap \& Agarwal, 2020). Similar outcomes are proposed by Adegbola (Adegbola, 2010), where impact assessment of the storage innovations should include indicators as income, health expenditures, food security and nutrition status. This is a very complex topic, since these dynamics between interventions and outcomes differ per product, production regime, region and part of the supply chain taken into consideration. There is no standard yet for these kind of assessments, and in literature a comprehensive impact assessment of an intervention with its effect on food system outcomes and sustainability indicators other than food loss itself is very hard to find.

We recommend that an estimation of an intervention's environmental impact should be performed by comparing the environmental impact of the new elements that will be introduced by the intervention against the situation pre-intervention. For this purpose, different methods are available, including lifecycle assessment (LCA), environmentally extended input-output (EEIO) models and carbon footprint analyses (Muller \& Sukhdev, 2018; Muth et al., 2019; Xu et al., 2015). Regarding the economic sustainability, an economic analysis can help in selecting interventions of which the expected benefits exceed the costs (Ellison et al., 2019). For this reason, we suggest to perform an a priori cost-benefit analysis which considers the whole funding costs of the intervention. The analysis may differ depending on the context, including the type of intervention, the level and the actors involved (i.e. public or private intervention) and if funding is available. If adoption of a best practice or of a technology is going to have a positive return of time and resources investments, investors will be more prone to participate and stakeholders will be more willing to adopt it and the adoption rate will be higher. When possible, cost-benefit analysis should also consider changes in agricultural markets and other indirect effects introduced by the intervention in the food system. The impact on these food system variables can also affect the critical success factors for the adoption of an intervention previously presented. For example, the intervention's economic impact relates to affordability and income impact while the socio-economic impact relates to accessibility, awareness and technical feasibility. Therefore, there is a relationship between the criteria and the food systems impacts.

The proposed way forward is not to set up new projects and include all the required input data, but rather evaluate existing case studies and its data to validate and develop a framework to evaluate interventions and inform decision-making on intervention selection. Data that are missing might be estimated or neglected otherwise. Using these case studies, insight is derived on the set of most relevant input variables, and from there statistic modelling might increase its performance to a higher level of explanation in variance of the adoption rate. 


\section{$4 \quad$ Case studies}

As described in the introduction, four case studies have been selected of loss-reducing interventions in LMIC contexts. Analysis of these cases with the proposed framework provides a proof-of-principle of the framework. Scoring of the different factors (positive, negative, neutral or uncertain) - as far as information was available - was done by the study authors, with validation by other experts. For use of the framework itself, such an assessment should be conducted by the stakeholder(s) intending to implement an intervention, to assess whether a (set of) interventions is likely to succeed. In this case, the user of the framework should assign scores to the factors himself, if needed with help of experts.

\subsection{Crates for tomatoes in Nigeria}

The first case is about a research project on tomatoes carried out in 2018 by Wageningen University \& Research in two different areas of Nigeria (M. G. Kok et al., 2019). Nigeria is the most populous country of sub-Saharan Africa, with an estimated population of about 190 million people and is one of the leading producers of tomatoes in Africa: in 2016 FAO ranked Nigeria as number one in areas planted with tomatoes and number four in the world. Tomatoes are important for Nigeria not only for its economic value but as well for its nutritional contribution, since it represent about $18 \%$ of the average consumption of vegetables in Nigerian daily diets.

Studies on PHLs of tomatoes in this country reported that relevant losses happen during the different post-harvest stages. The policy and strategy document of Nigeria's Federal Ministry of Agriculture and Rural Development reported post-harvest loss rates up to $60 \%$ for all perishable crops (M. G. Kok et al., 2019). Previous research estimated the postharvest loss of tomatoes in Nigeria to be between 25\% and 50\% (Bolarin \& Bosa, 2015; Ibeawuchi et al., 2015; Ugonna et al., 2015). Tomato losses are driven by various diseases, especially in the wet season, and by mechanical injuries, inadequate storage, unsuitable handling, faulty system of transport and delayed transportation to the retail market. Critical drivers of PHL reported by farmers are poor infrastructure conditions, unsuitable tomato varieties, and poor postharvest handling, while transporters were more concerned with poor infrastructure conditions, roadblocks, and poor postharvest handling (Plaisier et al., 2019).

The scope of the project in this case was to measure the current PHLs in the tomato value chain in Nigeria and to test and introduce a new packaging of tomatoes as an intervention to reduce these losses. This project was conducted in cooperation with Agrofair, N-N-Solutions and the International Fertilizer Development Centre (IFDC). The performance of the intervention was evaluated in terms of the reduction of loss in product volume as well as in loss in product quality.

The project started with scoping the sector and selecting the value chain stakeholders to be involved in this intervention. In this project a participatory approach was used, with some specific preferences with respect to stakeholders (Plaisier et al., 2019). The appropriate selection strategy of participants depended on the context, envisioned scope, and the project period and timing, but the selection was based on three criteria:

a) Participants are active actors actually working in the value chain in at least one of the activities, such as production, transportation, processing, trading, or retailing;

b) Participants are already trading with at least one other participant in the value chain;

c) Participants are willing to implement potential innovations to reduce PHL and are committed to participate for the entire project trial.

Imposing these participant selection criteria may help increase intervention adoption rate. A total of 51 value chain actors were selected. A participatory approach was then adopted to identify causes for PHLs in the supply chain and selecting potential solutions to address these causes. In particular, workshops and more informal exchange opportunities were held for gathering participants to discuss the different project phases. 
As stated in the previous section, participatory approaches should be categorized to clarify implicit effects on the adoption rate. Not only participation but also the pre-selection of participants is an important element for adoption. In all, the participatory approach was recognized as a powerful tool to improve the acceptability of interventions (Nastasi et al., 2000).

The intervention agreed upon was the transport of tomatoes in returnable plastic crates instead of in the usual raffia baskets (see Figure 3 below) to reduce losses. Crates can be stacked and are more stable, preventing mechanical damage to the tomatoes in handling and transportation. The solution not only had a $100 \%$ support base among the participants, but it also met the criteria of being specific, measurable, achievable (and affordable), realistic, and possible within the time boundaries of the project. So in this case, according to the proposed framework we have a micro-level intervention that could be classified as a mix of organization and (low) technology type developed through a participatory approach. A specific measurement tool for FLW was developed to evaluate the intervention impact (M. G. Kok et al., 2019). Three different pilot studies were conducted, two in the southern part of Nigeria and one in the northern part.

Crates were found to outperform baskets in both regions, resulting in reduced losses and less quality decay. Weight loss was between 5 and 12\% lower with crates than with baskets. Similarly, the loss in best-quality A-grade tomatoes was lower for tomatoes transported in crates (between $2 \%$ and $15 \%$ ) than the one transported in the baskets (between 27 and 37\%). Moreover, an experiment which simulated transport (Aba et al., 2012) found that the mechanical damage to tomatoes resulting from impact and vibration was lower when using plastic crates compared to when using raffia baskets. A large majority of participants $(87 \%)$ in the study preferred plastic crates to raffia baskets. After the evaluation pilot, the participants were provided the opportunity to purchase the plastic crates for half the price of a new crate. $67 \%$ of the participants bought the plastic crates they were using during the pilot at half the new purchasing price, and $22 \%$ bought not only the crates used in the pilot but also some additional ones. This indicates a high adoption rate of the implemented intervention with plastic crates and shows that it was a good fit for the local context. However, it was observed that not all actors could benefit equally from the crates introduction, with retailers and traders that had most of the financial gains. Moreover, no common agreement was reached about which actor should purchase and own the crates that would be used throughout the chain. Finally, an environmental assessment of plastic crates over raffia baskets, together with the economic impact on the local manufacturing of these baskets is missing.
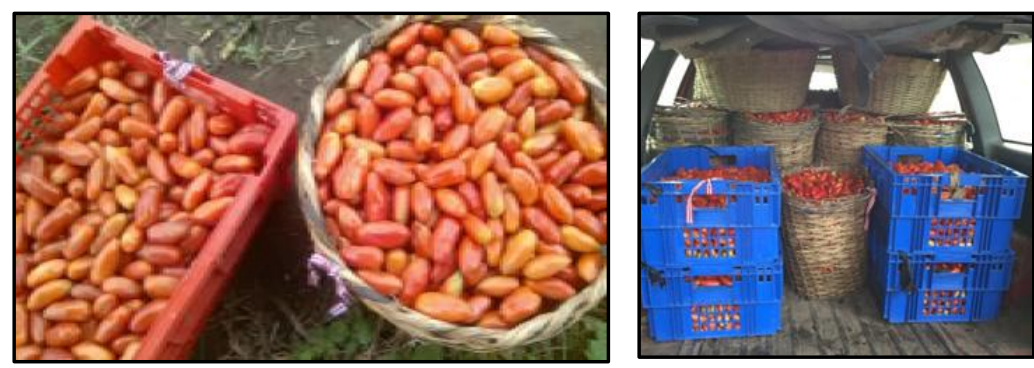

Figure 3 Tomato crates and raffia baskets (M. G. Kok et al., 2019).

Concerning the adoption criteria for intervention, the criteria were scored as outlined in Table 10 below. A "+" score indicates that the criterion was present, a "-" score indicates that the criterion was not present, a "+/-" score indicates ambiguity with regard to the criterion, and an empty box indicates that the information about the case was not sufficient to score on this criteria. In the middle column of the table, the score is motivated. 
Table 10 Scoring of adoption criteria for the Nigerian tomato case.

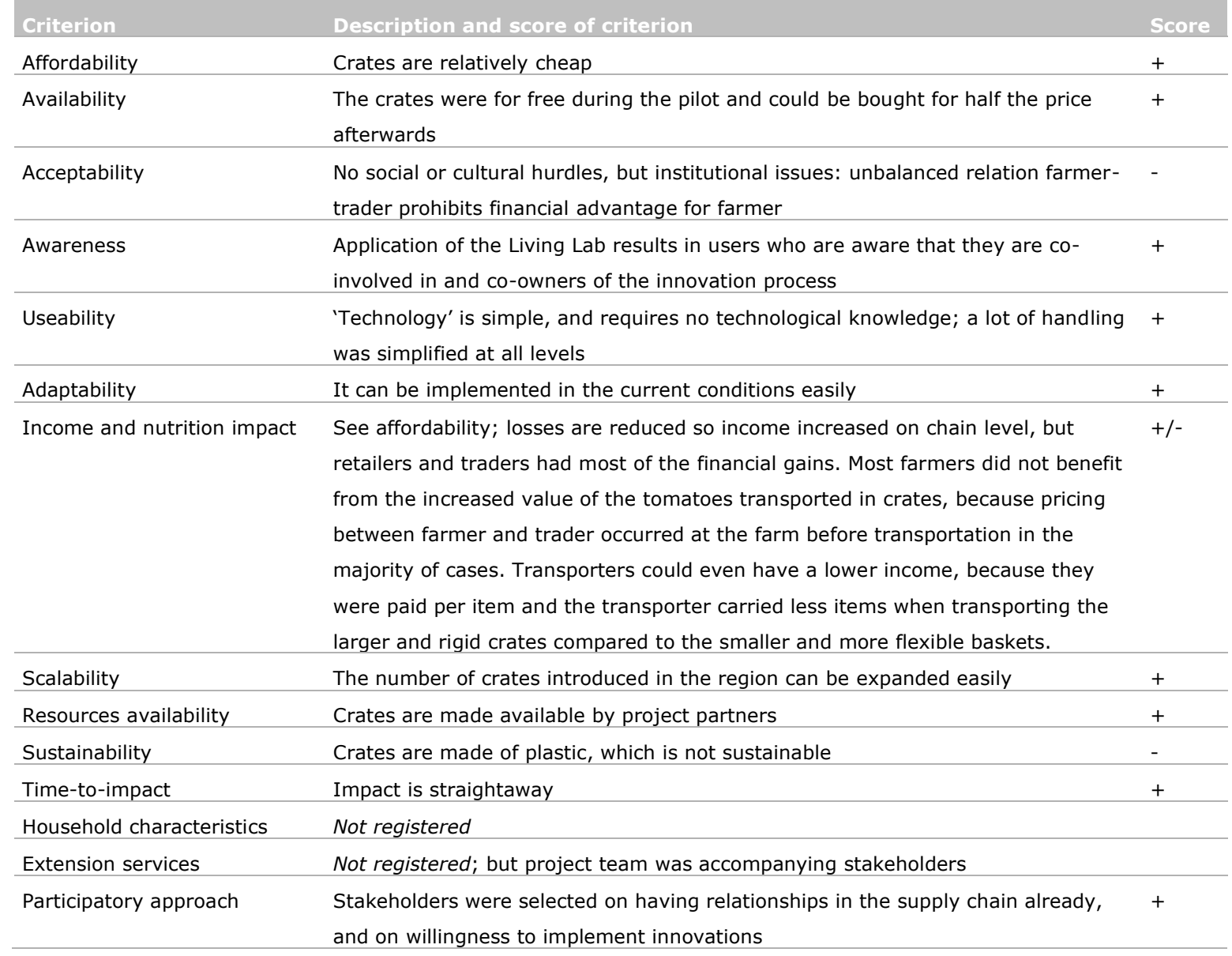

Note that the scores should not be interpreted as the impact on the level of adoption, but merely as the 'values' of the criteria that can be considered positive, neutral or negative with respect to a criterion.

The adoption rate turned out to be very high, which might be expected with a short-term, microlevel, low investment intervention like the crates, especially when the selected stakeholders already had some relationship in the supply chain and were willing to use the crates. Moreover, the crates showed to be effective in reducing quantitative and qualitative food losses. The appropriateness of the intervention for the context and the stakeholders' problems in the food chain, combined with the participatory approach taken in the implementation of the intervention contributed to the success of the intervention in this case.

\subsection{Maize storage in Benin}

This case study is based on a Ph.D. thesis on maize storage interventions in Benin (Adegbola, 2010). Maize is a major staple food and an important source of income and employment for many farmers in southern Benin. Pests make the storage of maize over long periods of time difficult and can compromise food security and lower the quality of grain destined for sale. At the time of the interventions, estimated quantity losses after six months of storage ranged from $17 \%$ to $40 \%$ of the total maize production (Adegbola \& Arouna, 2011). Adoption of storage innovations is key to food security and household income in Benin where farmers experience serious pest damage of maize in storage. 
In order to improve maize storage life, since 1992 improved storage facilities (wooden granaries) and Sofagrain $\AA$, an insecticide protectant, have been promoted. This was first done through a project funded by FAO and then by a second post-harvest project started in 1997 with the Agricultural Development Program (PADSA) supported by the Danish International Development Agency (DANIDA) and NGOs including Helvetas. However, after initial adoption, the practices were later abandoned: Of the farmers who adopted the improved wooden granary and Sofagrain $\AA$ in 2002 , six years later in

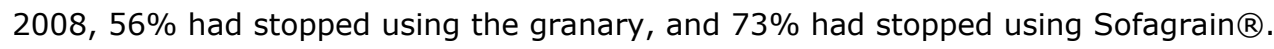

The research conducted by Adegbola (2010) addressed primarily the causes of the ineffectiveness of indigenous maize storage technologies. Using a participatory approach the most effective indigenous granary was improved (see Figure 4) and promoted together with Sofagrain ${ }^{\circledR}$, one of the best synthetic organophosphate insecticides for protecting grain, against insect attack during storage. Onfarm trials indicated that after six months of storage, the losses were reduced from $30 \%$ to only $5 \%$ for maize treated with Sofagrain $\AA$ and stored in an improved wooden granary. Moreover, extension programs were also established in the maize storage project to increase the probability of farmers to have positive perceptions on the quality provided by the storage. Also in this case we have a micro level intervention developed through a participatory approach that is a mix of (low) technology (the granary and Sofagrain $($ ) and best practices (proper use of this technology).

In the time period $1992-2001,45 \%$ of the participants started using an improved granary, $48 \%$ started using Sofagrain $\AA$, and $38 \%$ started using both. However, after 10 years the wooden granaries needed to be renewed and about 56\% of adopters of improved wooden granaries in 2002 did not replace it. There were two reasons for that: high costs and lack of building material in the region. Also Sofagrain $\AA$ was abandoned: $73 \%$ of the adopters in 2002 had abandoned its use by 2008 due to its high price and restricted availability. In this case, FAO and the NGOs involved had not anticipated farmers' other constraints regarding the adoption of storage innovations such as operating and investments costs, labour requirements in harvest season, and availability of conservation measures and building materials of granary. These constraints can prevent poor-resources farmers and those with limited family labour from taking advantage of the effectiveness of the storage innovations against pests.
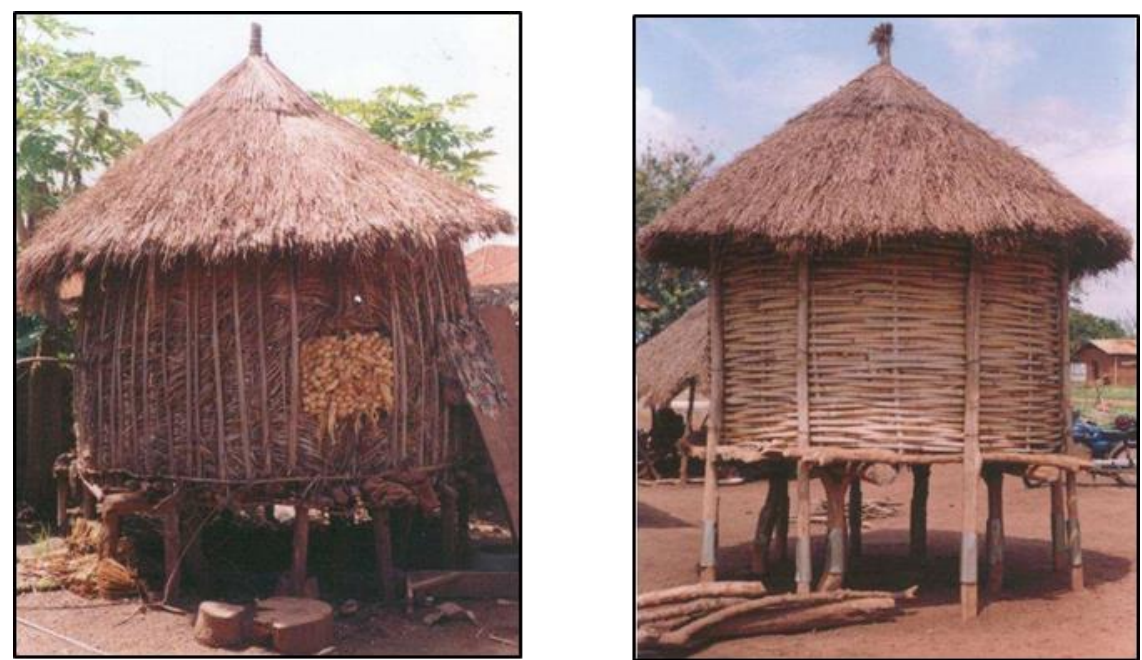

Figure 4 Old (left) and improved (right) indigenous maize storage (Adegbola \& Arouna, 2011).

Scoring the information available about the case of this food loss intervention along the framework of this study is summarized in the table below. A "+" score indicates that the criterion was present, a "-" score indicates that the criterion was not present, a "+/-" score indicates ambiguity with regard to the criterion, and an empty box indicates that the information about the case was not sufficient to score on this criteria. In the middle column of the table, the score is motivated. 
Table 11 Criteria and scores for the Benin maize storage case.

\begin{tabular}{|c|c|c|}
\hline Criterion & Description and score of criterion & Score \\
\hline Affordability & Storage had high construction cost, and insecticide was expensive & - \\
\hline Availability & The insecticide was not available after some time & - \\
\hline Acceptability & These aspects were not incorporated in the approach (see 'participatory approach') & \\
\hline Awareness & $\begin{array}{l}\text { This is studied here as a separate model, stating that awareness precedes technology } \\
\text { adoption in the first stage and continued use or abandonment later }\end{array}$ & \\
\hline Adaptability & $\begin{array}{l}\text { A storage is useful for remote farmers. Farmers with direct road access can reach the } \\
\text { market easily with small amounts and for them storage has less impact. }\end{array}$ & $+/-$ \\
\hline $\begin{array}{l}\text { Income and } \\
\text { nutrition impact }\end{array}$ & It is advised to take nutrition impact into account. & \\
\hline $\begin{array}{l}\text { Resources } \\
\text { availability }\end{array}$ & $\begin{array}{l}\text { The availability of building materials for the granary was not part of the project, neither was } \\
\text { the availability of labour }\end{array}$ & - \\
\hline Sustainability & Not addressed in this study & \\
\hline Time-to-impact & Impact of more income is after season, but feasibility takes more years & $+/-$ \\
\hline $\begin{array}{l}\text { Household } \\
\text { characteristics }\end{array}$ & Educational level had a positive impact on technology adoption & + \\
\hline Extension services & $\begin{array}{l}\text { Participation in the extension program of the project increases the } \\
\text { probability of farmers to have positive perceptions on the quality provided by the storage }\end{array}$ & + \\
\hline
\end{tabular}

From this scoring, we see that most of the critical factors underpinning successful adoption were not (or not strongly) present. This example can be considered a 'white elephant principle' because in the long run, the farmers did not seem to be able to maintain this infrastructure. Either they had no proper financial management (save some money for a new storage), or the intervention was not feasible. In the study it was mentioned that larger farmers adopted easier and showed more sustained adoption (less abandonment) than smaller farmers, which probably might relate to the required economies of scale for the storage capacity and the availability of financial resources because of their size. No feasibility study was mentioned in this research. The scoring of this intervention on our criteria (see the table) shows a case context not extremely suitable for the intervention. The outcome of the case shows that this could have been anticipated by mapping characteristics of the case context using our framework.

Another learning from this example is the need for a definition of adoption. In projects stakeholders like to participate (adopt interventions), since resources (investment, services) often are made available for them. Their costs are only 'time'. If during the project the financial situation of the stakeholders has not improved the continuation of using the intervention is likely to stop. In this case it is better to talk about temporary adoption. Interventions are really adopted if they continue to be applied independently from non-sustainable external resources.

\subsection{Good practices for cassava in Nigeria}

Cassava is a high volume root crop, important across Africa, and Nigeria is the largest producer in the world with 59 million tons produced in 2017. If harvested cassava roots (see Figure 5) cannot be marketed within two or three days of harvest then they may be processed into dried products of low quality, which have lower value. In this quality-based market this short shelf life leads to food losses. An estimated $28 \%$ of cassava in Nigeria is lost after harvest (COMCEC, 2016). However, based on a survey, a conservative estimate of on-farm losses is about 2-5\% in weight in Nigeria and with a total production of 45 million tonnes, these losses equal 900,000 to 2,250,000 tonnes of cassava roots per year. These losses were attributed mainly to low awareness of good harvesting practices. 
Since price is determined by product quality, losses are considered from an economic point of view as well by the Nigerians. Both men and women are involved in the production, processing and marketing of cassava, although men's emphasis is more on production and women's on processing.

In 2002-2004 the Presidential Initiative on Cassava was launched, followed by the Growth Enhancement Scheme. The goal of these initiatives was among others to promote cassava as a viable export crop and also to develop the production system to sustain the national demand. Interventions focused on the development of production, processing, and marketing of processed products (COMCEC, 2016). The government made fertilizers and seed (improved varieties) available, accessible and affordable to farmers at a subsidized rate. Additionally, investments were made in creating market linkages with processors and traders aimed at enhancing impact on socio-economic outcomes such as youth and women empowerment and poverty alleviation.
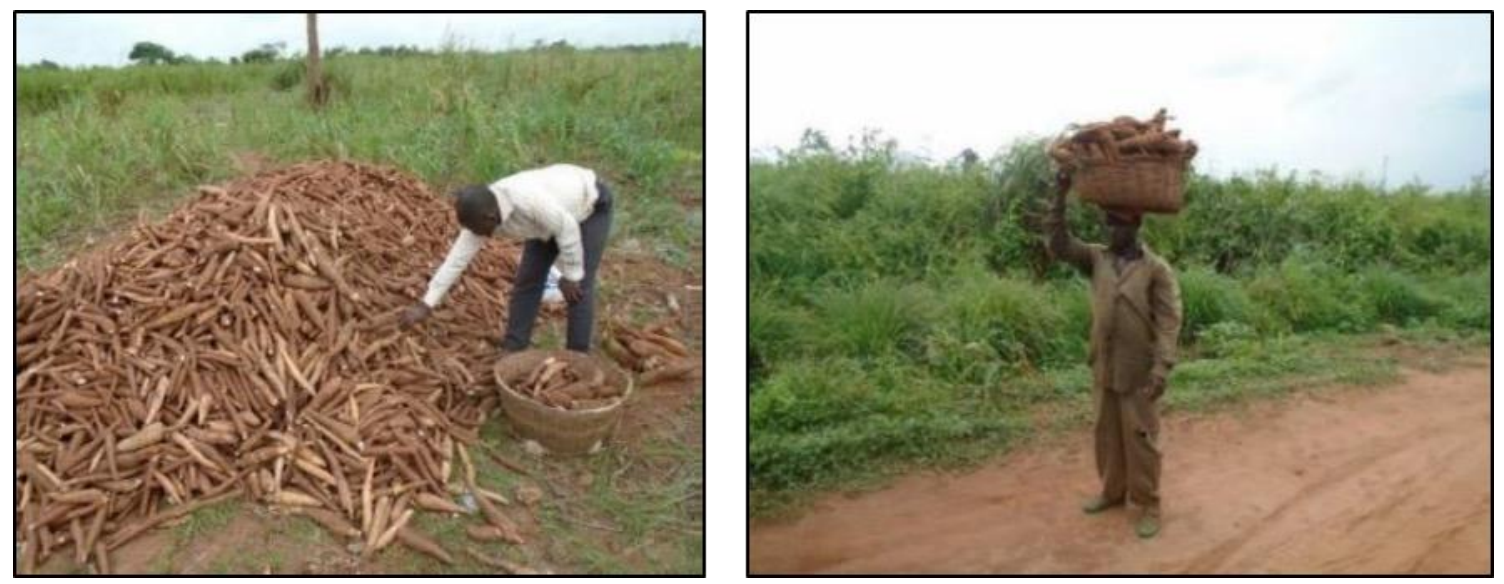

\section{Figure 5 Cassava waiting for transport in the sun (left) and on the way to transport vehicle (right) (COMCEC, 2016).}

In this case, the intervention in the Nigerian cassava sector took place on various levels, starting at the macro level. As part of a nationwide policy, new seeds were distributed, and good practices in the supply chain with a focus on farm level activities were communicated, including avoiding harvesting damage, sun protection after harvest, and curing before bagging or loading. Moreover, the policy program included price incentives for quality to increase quality awareness, and efforts to streamline value chain empowerment by mapping facilitators and barriers to these good practices (Butterworth et al., 2008; Tijani \& Umoh, 2016). Although women were positive about the governmental support, gender inequality in cassava production persisted.

The governmental support started in many states in Nigeria and continuity is different per state. E.g. in the Ogun State there is the Ogun State Cassava Revolution Programme (OGCRP) and hence the adoption for the farmers in this region is relatively easy and likely to persist into the future. For this case study no data were found on the reduction on food loss. Also, for the scoring of the criteria additional research was needed.

Table 12 Criteria and scores for the Nigerian cassava case.

\begin{tabular}{ll} 
Affiterion & Description and score of criterion \\
\hline Availability & The (local) government provided and still do provide all kinds of support for the cassava \\
\hline fcceptability & The government provides most of the resources \\
& The majority of women cassava farmers had favourable attitude towards the \\
& from the redemption centers due to some factors ranging from illiteracy, gender inequality \\
& and corruption \\
Awareness & Awareness was growing during the process of the governmental programme, since their \\
income and employment increased & + \\
\hline Useability & $\begin{array}{l}\text { The usability of seeds was fine, but good practices were documented, hence not } \\
\text { accessible for illiterate farmers, leading to less market linkage }\end{array}$
\end{tabular}




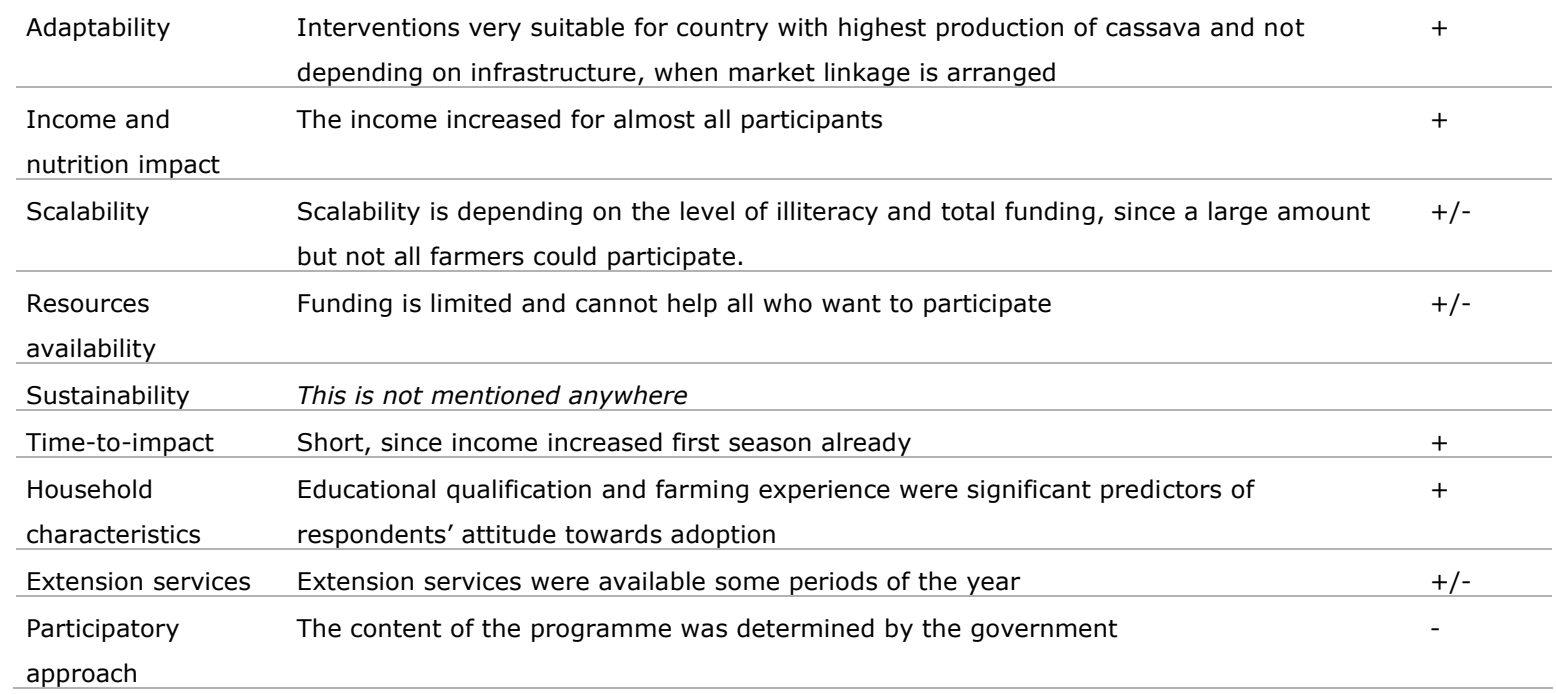

This case study shows that criteria can be strongly related to one another (e.g. 'awareness' being dependent on 'income'), which will often be the case. The intervention was targeted for the Nigerian people, however not all of them could profit from it. Like in the case study of crates for tomatoes in Nigeria, the selection of the target group for adoption affects the adoption rate. A suggestion for improving the analysis on relations between criteria and adoption rate is to include 'selection of participants', since, as shown in this case study, the target group is not always involved in a participatory approach. It is to be expected that in many cases interventions are targeted to a restricted group of the willing or a group with a certain potential, introducing a selection bias in an analysis of factors influencing the adoption rate.

\subsection{Shallot planting and curing in Indonesia}

In Indonesia, shallots are consumed in large quantities directly after harvest. In 2019, approximately 1.58 million tons of shallots were produced in Indonesia (FAO, 2020). Production concentrates on small farms ( $<1$ hectare) in Java, Lombok and Sumbawa during two main annual production seasons. Shallots are cured (leaf drying and forming of protective skin on the bulb) in-field, on the ground and are sealed by weight. Bulbs saved from the previous harvest are used as planting material for the new crop. For this, the seed bulbs often need to be stored for 4 to 6 months. Farmers are usually small and do not have access to sophisticated storage. As a result, they store up to 3 times more planting shallots than they need to compensate for the substantial storage losses they usually encounter since losses may vary between $35 \%$ and $70 \%$ according to a field survey (Palaz, 2020).

An on-farm intervention (microlevel) was set up to reduce post-harvest losses of these bulbs. The intervention was a mix of low technology and best practice type. The intervention was designed based on previous research in the area by the project partners and local consultants and included five phases: 1) an inception phase to sharpen the project's approach, 2) a selection phase to select those innovations that proved to be more feasible, desirable and viable for the market, 3) an adaptation phase where the technology and the inclusive business model were adapted to fit into the local context, 4) an acceleration phase where the selected innovations were implemented and, finally 5) an adoption phase in which the solution was improved and tested. The project included two different pilots and focused on developing sustainable innovations which are feasible for both farmers and other value chain actors further along the chain.

In the first phases of the project, it was highlighted that one of the main causes for losses was rot caused by fungi that enter the bulbs via the leaves before storage. For this reason, it was decided to implement improved curing to dry the neck of the bulbs by putting the shallots on bamboo racks which allows airflow. Improved storage was also implemented by avoiding heat during storage and introducing more ventilation and a strict sorting out of damaged shallots before entering storage. 
Finally, it was decided to improve cultivation by implementing the adoption of a dipping/fungal disease control procedure. Two pilot demonstrations were set up on the island of Sumbawa, in which participating farmers adapted these new technologies and practices with the aim to reduce storage losses. A total of 58 farmers was reached, 98 researchers, extension workers, and crop experts were involved, together with 26 members of the private sector. Participants received training based on visuals, registered data and a workshop and were interviewed to elicit their perception of the results. A joint voucher scheme for purchasing the fungicide at $50 \%$ of the price was introduced for the farmers to increase economic sustainability and to validate their 'willingness to pay'. Moreover, since in the first pilot it was noticed that farmers' trust was an issue, a behaviour change communication (BCC) strategy with different tools was developed to increase farmers awareness around the benefits of improved practices and help build capacity among farmers to apply those practices (Palaz, 2020).

The improved curing was found to be 4 days faster than drying on the ground leading to much betterquality seed bulbs for storage and to a $4.2 \%$ loss reduction. Improved storage and a stricter selection of storage bulbs led to a $6.3 \%$ reduction in storage loss in weight of seed bulbs and a better growth of the new crop. Finally, farmers recognized the benefits of dipping seed bulbs in a fungicide solution which resulted in a reduction of rot after planting from $20 \%$ to less than $5 \%$ that leads to approximately $20 \%$ more shallots in the field and an estimated $20 \%$ yield increase.

\section{Table 13 Criteria and scores for the Indonesian shallot case.}

\begin{tabular}{|c|c|c|}
\hline Criterion & Description and score of criterion & Score \\
\hline Affordability & $\begin{array}{l}\text { Racks for drying can be built easily and with cheap material (I.e. bamboo). } \\
\text { Dipping in fungicide is cheaper than spraying since less quantity is used. }\end{array}$ & + \\
\hline Availability & Fungicide is available and already been used by farmers. & + \\
\hline Acceptability & Farmers' trust had to be built & $+/-$ \\
\hline Awareness & $\begin{array}{l}\text { Farmers could see the benefits of the intervention and a BCC campaign was } \\
\text { organized to explain the intervention. }\end{array}$ & + \\
\hline Useability & 'Technology' is simple and requires no technological knowledge; & + \\
\hline Adaptability & Limited information & \\
\hline $\begin{array}{l}\text { Income and nutrition } \\
\text { impact }\end{array}$ & Limited information & \\
\hline Scalability & $\begin{array}{l}\text { The intervention is scalable since very little investments are needed for } \\
\text { building the drying racks. This can be done with cheap material and family } \\
\text { work. }\end{array}$ & + \\
\hline $\begin{array}{l}\text { Resources } \\
\text { availability }\end{array}$ & $\begin{array}{l}\text { Some of the fungicide provided through the voucher system, but it's } \\
\text { normally used by farmers. }\end{array}$ & + \\
\hline Sustainability & Limited information & \\
\hline Time-to-impact & $\begin{array}{l}\text { Drying impact is straightaway. For the dipping, a positive impact was } \\
\text { observed during the primary production by the farmers. Limited evidence, } \\
\text { but farmers came up with clear positive difference. }\end{array}$ & + \\
\hline $\begin{array}{l}\text { Household } \\
\text { characteristics }\end{array}$ & Limited information & \\
\hline Extension services & $\begin{array}{l}\text { Local extension service was available but the study reported limited } \\
\text { efficancy. }\end{array}$ & $+/-$ \\
\hline $\begin{array}{l}\text { Participatory } \\
\text { approach }\end{array}$ & The solution was brought to farmers and not developed in collaboration. & - \\
\hline
\end{tabular}

The project also claimed to have a positive effect on environmental impact since not only reduced PHLs but as well less fungicide was used with the dipping method proposed and more yield was obtained per hectare. A full cost-benefits analysis was not performed but since costs of the intervention are very limited (i.e. fungicide was already used by farmers and cheap available material can be used for racks construction) while benefits are less losses and more production, the economic sustainability of the project is positive. This was confirmed by farmers reporting that by applying these best practices they had less losses during cultivation and storage, and that they didn't need to buy shallots bulbs for planting for the new season. 
In conclusion, across the case studies we observe that sustained adoption becomes very unlikely when larger investments or expenditures are required that exceed the financial capacity of the stakeholders involved. This highlights the importance of interventions appropriate for the users' level of resources, but also the fact that often combinations of interventions (e.g. improving access to credit as well as making technology available) to support sustained adoption. 


\section{$5 \quad$ Conclusions and further research}

This study developed a framework to categorize food loss reducing interventions and to evaluate their implementation based on success factors driving adoption and on their sustained use and impact. We defined success in terms of an intervention resulting in a reduction in food losses and being successfully adopted to the extent that this impact can be realized. Even with interventions with proven impact in other contexts, adoption and sustained use are critical to realize food loss reduction in the implementation context. Therefore, we focused on the factors that determine whether a food loss-reducing intervention is adopted. In the four case studies to which the framework was applied, we showed that scoring contextual factors using this framework produced a good indication of conduciveness of the case context to these particular interventions. The intervention evaluations made with the use of the framework and the intervention outcomes in the cases corresponded quite closely. Therefore, the factors included in the framework prove to be important determinants of an intervention's sustained adoption and impact, even in a qualitative application.

In this paper the adoption rate of food loss reducing interventions was analyzed in relation to a set of criteria, that arose from literature. Until now causalities between criteria and intervention adoption were investigated with a restricted subset of the criteria as presented in paragraph 3.4.1. This paper showed from the collection of criteria in literature, that a non-uniform view on this topic can be ascertained, and therefore a more extended approach to criteria collection in the existing cases from literature is advised, using the collected set in this paper. The complexity of the challenge to predict at some level the adoption rate of an intervention does not only arise from the qualitative nature of the criteria, but also from the interdependency of some of these criteria. Furthermore, in addition to literature, a criterion with respect to the process of the intervention introduction is put forward: 'the participatory approach'. It consists of two elements, the selection of the participants and the level of participation. Both are crucial to the adoption rate, and from an analytical point of view could be treated as two separate criteria.

The LMIC context was highlighted specifically, due to food losses being particularly relevant for these countries (in high-income countries food waste being a quantitatively bigger problem), and the considerable deficiencies in the smallholder-driven food supply chains. Due to the highly limited resources and capabilities of small actors in these chains, we expect the criteria proposed to be particularly relevant for LMIC. Factors such accessibility, affordability, awareness, extension services, and information are anything but a given for smallholder farmers in LMICs, whereas food production in high income countries is typically a business of large-scale farming, conducted by farmers and organizations with the relevant resources, capabilities, and (financial) institutional access.

Truly understanding the localized drivers of adoption of food loss-reducing interventions is complex. Until now, not much research covered this topic comprehensively, and this paper is just one step further in unravelling the characteristics that influence the human behavior in this context. The intervention examples provided are by no means exhaustive, but serve as an indication of the variety of (mostly low- and mid-tech) interventions that are being implemented in LMIC contexts. Also the criteria proposed are by no means exhaustive or with their definition set in stone. More detailed research is needed into the importance of individual factors, as well as research into how these factors can be operationalized quantitatively. Future research should also look into how intervention characteristics and case contextual variables produce a match or mismatch that determines the successful and sustained adoption of an intervention. How, why, under what circumstances, and the extent to which contextual factors operate as barriers or facilitators to interventions' success are the main questions to be addressed.

The challenge is big, but based on a more complete and extensive data, statistical analyses can provide prevailing elements in the context of prediction of the success of a food loss reduction intervention and its adoption rates. Also, this study has shown that a qualitative evaluation, working with the information that is available, does well in explaining an intervention's adoption or lack thereof. 
In conclusion, sustained adoption of a food loss-reducing intervention critically depends on the financial capacity of the user to use and maintain the intervention independently, and the appropriateness of the intervention for the local food system. This shows the multi-dimensional and intertwined nature of the drivers of postharvest losses, and stresses the need for combinations of interventions that address all these drivers. Much work remains to be done to address postharvest losses, however the insights from this paper can help inform these much-needed integral intervention strategies - with interventions of different types and of different levels with different coalitions of stakeholders - in order to successfully reduce food loss and contribute to more sustainable food system outcomes. 


\section{Literature}

Aba, I. P., Gana, Y. M., Ogbonnaya, C., \& Morenikeji, O. O. (2012). Simulated transport damage study on fresh tomato (Lycopersicon esculentum) fruits. Agricultural Engineering International: CIGR Journal, 14(2), 119-126.

Adegbola, P. (2010). Economic Analyses of Maize Storage Innovations in Southern Benin [Wageningen University]. http://library.wur.nl/WebQuery/clc/1936631

Adegbola, P., \& Arouna, A. (2011). Acceptability of maize improved storage structures in Southern Benin. Bulletin de la Recherche Agronomique du Benin, 13.

Affognon, H., Mutungi, C., Sanginga, P., \& Borgemeister, C. (2014). Unpacking Postharvest Losses in SubSaharan Africa: A Meta-Analysis. 20.

Affognon, H., Sanginga, P., Mutungi, C., \& Borgemeister, C. (2015). Unpacking postharvest losses in subSaharan Africa: a meta-analysis. World Development, 66, 49-68. https://doi.org/10.1016/j.worlddev.2014.08.002

Akande, G., \& Diei-Ouadi, Y. (2010). Post-harvest losses in small-scale fisheries - Case studies in five subSaharan African countries. 89.

AUC. (2014). Malabo Declaration on Accelerated Agricultural Growth and Transformation for Shared Prosperity and Improved Livelihoods.

Berkum, S. van, Dengerink, J., Ruben, R., van Berkum, S., Dengerink, J., \& Ruben, R. (2018). The food systems approach: sustainable solutions for a sufficient supply of healthy food. Wageningen Economic Research, 064(June), 32. https://doi.org/10.18174/451505

Bolarin, F. M., \& Bosa, S. (2015). Post Harvest Losses: A Dilemma in Ensuring Food Security in Nigeria. Journal of Natural Sciences Research, 5(7), 2225-2921. http://www.iiste.org/Journals/index.php/JNSR/article/viewFile/21502/22098

Butterworth, R., Abdulsalam-Saghir, P., \& Martin, A. (2008). Gender and diversity report - Nigeria. September. http://www.nri.org/images/Programmes/gender-and-socialdifference/publications/Nigeria_GDSituationalAnalysis.pdf

Clark, L. F., \& Hobbs, J. E. (2018). Beyond the Farm Gate: Postharvest Loss and the Role of Agro-Processors in Sub-Saharan African Food Security. 10.

COMCEC. (2016). Reducing On-Farm Food Losses In the OIC Member Countries. 169.

Costa, S. J. (2014). Reducing Food Losses in Sub-Saharan Africa (improving Post-Harvest Management and Storage Technologies of Smallholder Farmers.).

Ellison, B., Muth, M. K., \& Golan, E. (2019). Opportunities and Challenges in Conducting Economic Research on Food Loss and Waste. Applied Economic Perspectives and Policy, 41(1), 1-19. https://doi.org/https://doi.org/10.1093/aepp/ppy035

FAO. (2011). Global food losses and food waste. Extent, causes and prevention. https://doi.org/10.4337/9781788975391

FAO. (2014). Food loss assessments: Causes and solutions - Kenya - Banana, Maize, Milk, Fish. 89.

FAO. (2015). The state of food insecurity in the world. https://doi.org/10.1007/BF00428044

FAO. (2019a). Food Loss Index. http://www.fao.org/food-loss-and-food-waste/ flw-data

FAO. (2019b). The state of food and agriculture. 182.

FAO. (2020). FAOstat. http://www.fao.org/faostat/en/

Fattibene, D., Recanati, F., Dembska, K., \& Antonelli, M. (2020). Urban food waste: A framework to analyse policies and initiatives. Resources, 9(9), 1-18. https://doi.org/10.3390/RESOURCES9090099

Flanagan, K., Robertson, K., \& Hanson, C. (2019). Reducing food loss and waste - Setting a Global Action Agenda. 136.

Global Knowledge Initiative. (2014). Reducing Global Food Waste and Spoilage. 58.

Guo, J., Mao, K., Zhao, Y., Lu, Z., \& Lu, X. (2019). Impact of Climate on Food Security in Mainland China: A New Perspective Based on Characteristics of Major Agricultural Natural Disasters and Grain Loss. 25.

Guo, X., Broeze, J., Groot, J., Axmann, H., \& Vollebregt, M. (2020). A worldwide hotspot analysis on food loss and waste, associated greenhouse gas emissions, and protein losses. Sustainability, 12, 7488.

Hanson, C., Flanagan, K., Robertson, K., Axmann, H., Bos-Brouwers, H., Broeze, J., Kneller, C., Maier, D., McGee, C., O'Connor, C., Sonka, S., Timmermans, T., Vollebregt, M., \& Westra, E. (2019). Reducing food loss: Ten interventions to scale impact. 84.

HLPE. (2013). Investing in smallholder agriculture for food security.

HLPE. (2014). Food losses and waste in the context of sustainable food systems. A Report by the High Level Panel of Experts on Food Security and Nutrition of the Committee on World Food Security. of Sustainable Food Systems, June, 117. http://www.fao.org/3/a-i3901e.pdf 
Hodges, R. (2013). How to assess postharvest cereal losses and their impact on grain supply. Rapid weight loss estimation and the calculation of cumulative cereal losses with the support of APHLIS.

Hodges, R. J., Buzby, J. C., \& Bennett, B. (2010). Postharvest losses and waste in developed and less developed countries: opportunities to improve resource use. 9.

Ibeawuchi, I. I., Okoli, N. A., Alagba, R. A., Ofor, M. O., Emma-Okafor, L. C., Peter-Onoh, C. A., \& Obiefuna, J. C. (2015). Fruit and Vegetable Crop Production in Nigeria: The Gains, Challenges and The Way Forward. Journal of Biology, Agriculture and Healthcare, 5(2), 194-209.

Ika, L. A. (2019). Project Management for Development in Africa: Why Projects Are Failing and What Can Be Done About It. 15.

IPCC. (2020). Climate Change and Land. An IPCC special report on climate change, desertification, land degradation, sustainable land management, food security, and greenhouse gas fluxes in terrestrial ecosystems. https://doi.org/10.1002/9781118786352.wbieg0538

Kashyap, D., \& Agarwal, T. (2020). Food loss in India: water footprint, land footprint and GHG emissions. Environment, Development and Sustainability, 22(4), 2905-2918. https://doi.org/10.1007/s10668019-00325-4

Khalil, C. A., Conforti, P., Ergin, I., \& Gennari, P. (2017). Defining Small-Scale Food Producers To Monitor Target 2.3. of the 2030 Agenda for Sustainable Development. FAO Statistics Working Paper Series, 17(12), 1-51. www.fao.org/3/a-i6858e.pdf

Kimiywe, J. (2015). Food and nutrition security: Challenges of post-harvest handling in Kenya. Proceedings of the Nutrition Society, 74(4), 487-495. https://doi.org/10.1017/s0029665115002414

Kitinoja, L. (2013). Use of cold chains for reducing food losses in developing countries. 16.

Kitinoja, L., Saran, S., Roy, S. K., \& Kader, A. A. (2011). Postharvest technology for developing countries: challenges and opportunities in research, outreach and advocacy. 7.

Klink, R. (2015). Adaptation of post-harvest loss interventions. A case study in the Gulu and Oyam district, Northern Uganda (Issue March). Wageningen University.

Kok, M., Castelein, B., Broeze, J., \& Snels, J. (2021). Working paper-Pragmatic and intergrative approach for food loss and waste monitoring, analysis of causes and interventions.

Kok, M. G., Groot, J. J., Dastoum, S., Plaisier, C., Dijkxhoorn, Y., \& Wagenberg, C. P. A. van. (2019). A Measurement tool on Food losses and Waste - Applied in a tomato value chain in Nigeria. 34.

Kumar, D., \& Kalita, P. (2017). Reducing postharvest losses during storage of grain crops to strengthen food security in developing countries. Foods, 6(1), 8. internal-pdf://0259434457/15.pdf

Lassen, A. D., Christensen, L. M., \& Trolle, E. (2020). Development of a danish adapted healthy plant-based diet based on the EAT-lancet reference diet. Nutrients, 12(3), 2013-2014. https://doi.org/10.3390/nu12030738

Lipinski, B, Hanson, C., Lomax, J., Kitinoja, L., Waite, R., \& Searchinger, T. (2016). Toward a sustainable food system Reducing food loss and waste. World Resource Institute, June, 1-40. http://unep.org/wed/docs/WRI-UNEP-Reducing-Food-Loss-andWaste.pdf\%5Cnhttp://ebrary.ifpri.org/cdm/ref/collection/p15738coll2/id/130211

Lipinski, Brian, Clowes, A., Goodwin, L., Hanson, C., Swannell, R., \& Mitchell, P. (2017). SDG Target 12.3 on food loss and waste: 2017 progress report.

Lipinski, Brian, Hanson, C., Lomax, J., Kitinoja, L., Waite, R., \& Searchinger, T. (2013). Working paper Installment 2 of "Creating a Sustainable Food Future" - Reducing Food Loss and Waste. 40.

Muller, A., \& Sukhdev, P. (2018). Measuring what matters in agriculture and food systems. A synthesis of the results and recommendations of TEEB for Agriculture and Food's Scientific and Economic Foundations Report.

Muth, M. K., Birney, C., Cuéllar, A., Finn, S. M., Freeman, M., Galloway, J. N., Gee, I., Gephart, J., Jones, K., Low, L., Meyer, E., Read, Q., Smith, T., Weitz, K., \& Zoubek, S. (2019). A systems approach to assessing environmental and economic effects of food loss and waste interventions in the United States. Science of the Total Environment, 685, 1240-1254. https://doi.org/10.1016/j.scitotenv.2019.06.230

Nastasi, B. K., Varjas, K., Schensul, S. L., Silva, K. T., Schensul, J. J., \& Ratnayake, P. (2000). The Participatory Intervention Model: A Framework for Conceptualizing and Promoting Intervention Acceptability. School Psychology Quarterly, 15(2), 207-232. https://doi.org/10.1037/h0088785

Ndombi Waudo, J., \& Schripsema, A. (2015). Study of Food Losses and Loss Reduction Opportunities in Fruits and Vegetable Chains in Kenya - An ssessment of potato, courgette and avocado supply chains. 68.

Odoli, C. O., Owiti, H., Kobingi, N., Obiero, M., Ogari, Z., Mugo, J., Nyamweya, C., \& Aura, C. M. (2018). Post-harvest interventions in small-scale fisheries: a boon or bane to food and nutritional security in Kenya? 14.

Owach, C., Bahiigwa, G., \& Elepu, G. (2017). Factors Influencing the Use of Food Storage Structures by Agrarian Communities in Northern Uganda. Journal of Agriculture, Food Systems, and Community Development, February 2017, 1-18. https://doi.org/10.5304/jafscd.2017.072.003 
Owino, W. (2013). AVRDC - The world vegetable center's stakeholders workshop report on postharvest handling of vegetables in Kenya: Postharvest loss assessment results review and prioritization of interventions. 29.

Palaz, I. (2020). Turn losses into gain - reducing postharvest losses in shallots in Indonesia. AgriProFocus.

Plaisier, C., Sibomana, M., van der Waal, J., Clercx, L., van Wagenberg, C. P. A., \& Dijkxhoorn, Y. (2019). Approach for designing context-specific, locally owned interventions to reduce postharvest losses: Case study on tomato value chains in Nigeria. Sustainability (Switzerland), 11(1). https://doi.org/10.3390/su11010247

Searchinger, T., Richard, W., Craig, H., \& Janet, R. (2018). Word Resources Report - Creating a Sustainable Food Future. Worlds Resources Institute, December, 1-96.

Shiri, M. (2019). Small scale postharvest handling techniques for fruits, vegetables, roots, tubers and grains - Principles and practices. 39.

Sibomana, M. S., Workneh, T. S., \& Audain, K. (2016). A review of postharvest handling and losses in the fresh tomato supply chain: a focus on Sub-Saharan Africa. Food Security, 8(2), 389-404. https://doi.org/10.1007/s12571-016-0562-1

Siyoum, A. D. (2012). Broken promises - Food security interventions and rural livelihoods in Ethiopia (p. 174).

Stathers, T., Holcroft, D., Kitinoja, L., Mvumi, B. M., English, A., Omotilewa, O., Kocher, M., Ault, J., \& Torero, M. (2020). A scoping review of interventions for crop postharvest loss reduction in subSaharan Africa and South Asia. Nature Sustainability, 3(10), 821-835. https://doi.org/10.1038/s41893-020-00622-1

Tarabay, P. A., Chahine-Tsouvalakis, H., Tawk, S. T., Nemer, N., \& Habib, W. (2018). Reduction of food losses in Lebanese apple through good harvesting and postharvest practices. 7.

Tefera, T., Mugo, S., \& Beyen, Y. (2016). Developing and deploying insect resistant maize varieties to reduce pre-and post-harvest food losses in Africa. 10.

Tijani, S. A., \& Umoh, I. E. (2016). Attitude of Women Cassava Farmers Towards Participation in Growth Enhancement Support Scheme in Oyo state, Nigeria. 15.

Trienekens, J. H. (2011). Agricultural value chains in developing countries a framework for analysis. International Food and Agribusiness Management Review, 14(2), 51-82.

Ugonna, C., Jolaoso, M., \& Onwualu, A. (2015). Tomato Value Chain in Nigeria: Issues, Challenges and Strategies. Journal of Scientific Research and Reports, 7(7), 501-515. https://doi.org/10.9734/jsrr/2015/16921

UNEP. (2021). Food Waste Index Report 2021. In Unep.

United Nations. (2015a). Transforming our world: The 2030 agenda for sustainable development. https://sustainabledevelopment.un.org/content/documents/21252030 Agenda for Sustainable Development web.pdf

United Nations, D. of E. and S. A. P. D. (2015b). Population 2030: Demographic challenges and opportunities for sustainable development planning (ST/ESA/SER.A/389). United Nations, 58. http://www.un.org/en/development/desa/population/publications/pdf/trends/Population2030.pdf, date accessed 27th August, 2017

Vanlauwe, B., Coyne, D., Gockowski, J., Hauser, S., Huising, J., Masso, C., Nziguheba, G., Schut, M., \& Van Asten, P. (2014). Sustainable intensification and the African smallholder farmer. Current Opinion in Environmental Sustainability, 8, 15-22. https://doi.org/10.1016/j.cosust.2014.06.001

Verschoor, J. A., Oostewechel, R. J. A., Koenderink, N. J. J. P., Pereira da Silva, F. I. D. G., \& Hetterscheid, S. (2020). Postharvest interventions, key for improvement of food systems. Exploring the impact of postharvest interventions on increasing food availability, stability and income generation in developing economies. https://doi.org/https://doi.org/10.18174/535929

Viola, A. (2017). Scaling Up Post-Harvest Losses Interventions in Uganda Through Market Forces. 57. https://www.hks.harvard.edu/sites/default/files/degree programs/MPP/files/17 3 MPP_PAE_Agustin Viola_Scaling Up Post-Harvest Losses Interventions in Uganda Through Market Forces.pdf

Widyastuti, C. A., Hastarini, M. D., \& Indonesia, S. N. (2017). Report on Knowledge, Stakeholder and Network Mapping - Tropical Fruit. 35.

Xu, Z., Sun, D. W., Zhang, Z., \& Zhu, Z. (2015). Research developments in methods to reduce carbon footprint of cooking operations: A review. Trends in Food Science and Technology, 44(1), 49-57. https://doi.org/10.1016/j.tifs.2015.03.004

Xue, L., Liu, G., Parfitt, J., Liu, X., Van Herpen, E., Stenmarck, A., O'Connor, C., Östergren, K., \& Cheng, S. (2017). Missing Food, Missing Data? A Critical Review of Global Food Losses and Food Waste Data. Environmental Science and Technology, 51(12), 6618-6633. https://doi.org/10.1021/acs.est.7b00401 

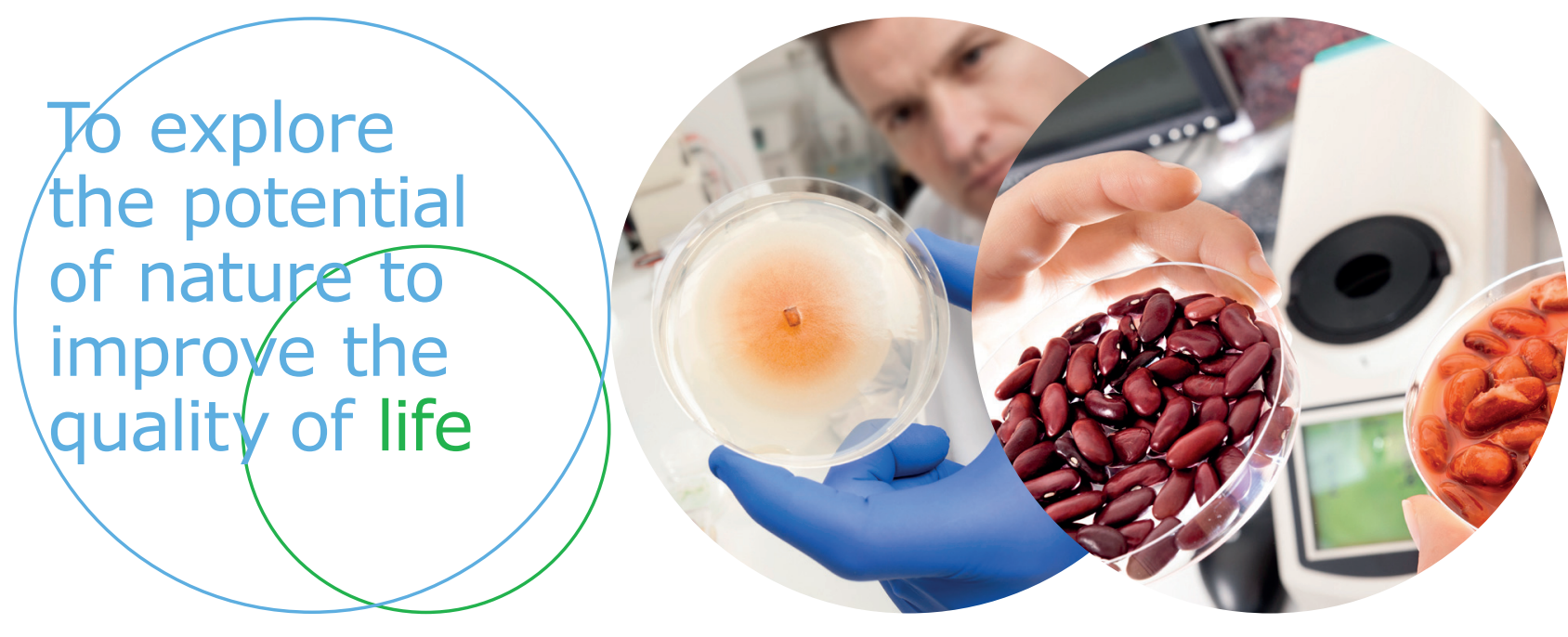

Wageningen Food \& Biobased Research Bornse Weilanden 9

6708 WG Wageningen

The Netherlands

www.wur.eu/wfbr

Einfo.wfbr@wur.nl

Report 2196
The mission of Wageningen University \& Research is "To explore the potential of nature to improve the quality of life". Under the banner Wageningen University \& Research, Wageningen University and the specialised research institutes of the Wageningen Research Foundation have joined forces in contributing to finding solutions to important questions in the domain of healthy food and living environment. With its roughly 30 branches, 6,800 employees (6,000 fte) and 12,900 students, Wageningen University \& Research is one of the leading organisations in its domain. The unique Wageningen approach lies in its integrated approach to issues and the collaboration between different disciplines. 